DOI:10.22337/2587-9618-2018-14-3-83-102

\title{
ABOUT WAVELET-BASED MULTIGRID NUMERICAL METHOD OF STRUCTURAL ANALYSIS WITH THE USE OF DISCRETE HAAR BASIS
}

\author{
Marina L. Mozgaleva ${ }^{1}$, Pavel A. Akimov 2,3,4,5, Taymuraz B. Kaytukov 2,6 \\ ${ }^{1}$ National Research Moscow State University of Civil Engineering, Moscow, RUSSIA \\ ${ }^{2}$ Russian Academy of Architecture and Construction Sciences, Moscow, RUSSIA \\ ${ }^{3}$ Scientific Research Center "StaDyO", Moscow, RUSSIA \\ ${ }^{4}$ Tomsk State University of Architecture and Building, Tomsk, RUSSIA \\ ${ }^{5}$ Peoples' Friendship University of Russia, Moscow, RUSSIA \\ ${ }^{6}$ Central Institute for Research and Design of the Ministry of Construction and Housing and Communal Services \\ of the Russian Federation, Moscow, RUSSIA
}

\begin{abstract}
The distinctive paper is devoted to so-called multigrid (particularly two-grid) method of structural analysis based on discrete Haar basis (one-dimensional, two-dimensional and three-dimensional problems are under consideration). Approximations of the mesh functions in discrete Haar bases of zero and first levels are described (the mesh function is represented as the sum in which one term is its approximation of the first level, and the second term is so-called complement (up to the initial state) on the grid of the first level). Special projectors are constructed for the spaces of vector functions of the original grid to the space of their approximation on the first-level grid and its complement (the refinement component) to the initial state. Basic scheme of the twogrid method is presented. This method allows solution of boundary problems of structural mechanics with the use of matrix operators of significantly smaller dimension. It should be noted that discrete analogue of the initial operator equation is a system of linear algebraic equations which is constructed with the use of finite element method or finite difference method. Block Gauss method can be used for direct solution.
\end{abstract}

Keywords: structural analysis, wavelet analysis, numerical methods, multigrid methods, two-grid method, discrete Haar basis, reduction, local structural analysis, approximation, boundary problem

\section{О ВЕЙВЛЕТ-РЕАЛИЗАЦИИ МНОГОСЕТОЧНОГО ЧИСЛЕННОГО МЕТОДА РАСЧЕТА КОНСТРУКЦИЙ НА ОСНОВЕ ДИСКРЕТНОГО БАЗИСА ХААРА}

\author{
М.Л. Мозгалева ${ }^{1}$, П.А. Акимов ${ }^{2,3,4,5}$, Т.Б. Кайтуков ${ }^{2,6}$ \\ ${ }^{1}$ Национальный исследовательский Московский государственный строительный университет, \\ г. Москва, РОССИЯ \\ ${ }^{2}$ Российская академия архитектуры и строительных наук, г. Москва, РОССИЯ \\ ${ }^{3}$ Научно-исследовательский центр СтаДиО, г. Москва, РОССИЯ \\ 4 Томский государственный архитектурно-строительный университет, г. Томск, РОССИЯ \\ ${ }^{5}$ Российский университет дружбы народов, г. Москва, РОССИЯ \\ ${ }^{6}$ Центральный научно-исследовательский и проектный институт \\ Министерства строительства и жилищно-коммунального хозяйства, г. Москва, РОССИЯ
}

\begin{abstract}
Аннотация: Настоящая статья посвящена так называемому многосеточному (в частности, двухсеточному) методу расчета строительных конструкций, основанному на использовании дискретного базиса Хаара (рассматриваются одномерные, двумерные и трехмерные задачи). Описана аппроксимации сеточных функций на нулевом и первом уровнях дискретного базиса Хаара (сеточная функция представляется в виде суммы, в которой первое слагаемое соответствует аппроксимации на первом уровне, а второе слагаемое представляет собой так называемую детализацию (дополнение до исходного состояния) на сетке первого уровня. Строятся специальные проекторы пространства векторных функций на исходной стеке на пространство их аппроксимаций на сетке первого уровня и детализацию (дополнение до исходного состояния). Изложена общая схема двухсеточного метода. Данный метод позволяет решать краевые за-
\end{abstract}


дачи строительной механики с использованием соответствующих матричных операторов существенно меньшей размерности. Следует отметить, что дискретным аналогом исходного операторного уравнения является система линейных алгебраических уравнений, формируемая с использованием техники метода конечных элементов или метода конечных разностей. Для прямого решения указанной системы может использоваться блочный метод Ланцоша.

Ключевые слова: расчеты строительных конструкций, вейвлет-анализ, численные методы, многосеточные методы, двухсеточный метод, дискретный базис Хаара, редукция, локальный расчет конструкций, аппроксимация, краевая задача

\section{ONE-DIMENSIONAL PROBLEMS}

\subsection{About alternative discrete basis.} Let us consider the following functions: - father wavelet (Figure 1),

$$
\Phi(x)=\left\{\begin{array}{l}
1,0 \leq x<1 \\
0, x<0 \vee x \geq 1
\end{array}\right.
$$

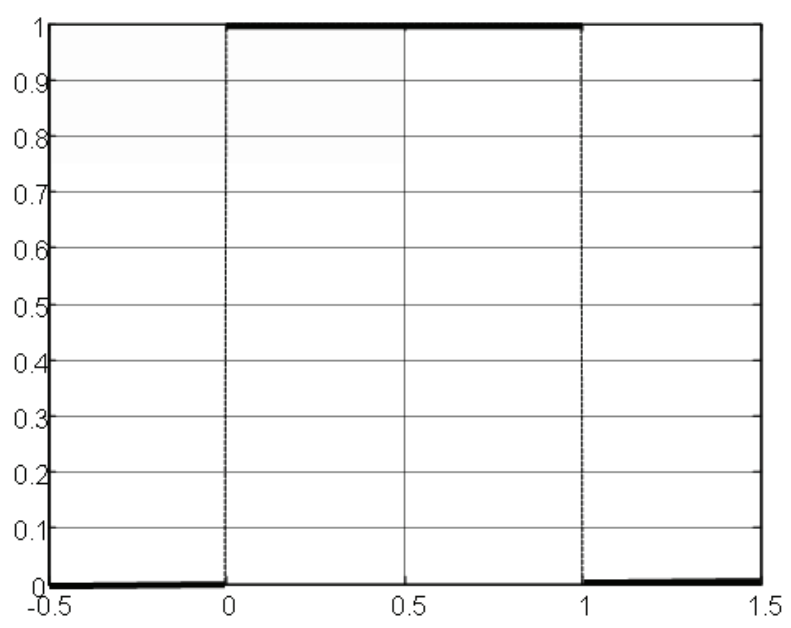

Figure 1. Father wavelet.

- the first mother wavelet (Figure 2),

$$
\Psi_{1}(x)=\left\{\begin{array}{l}
1, \quad 0 \leq x<1 / 3 \\
-1, \quad 2 / 3 \leq x<1 \\
0, \quad x<0 \vee 1 / 3 \leq x<2 / 3 \vee x \geq 1
\end{array}\right.
$$

- the second mother wavelet (Figure 3) i.e. variant of French Hat,

$$
\Psi_{1}(x)=\left\{\begin{array}{l}
-1, \quad 0 \leq x<1 / 3 \vee 2 / 3 \leq x<1 \\
2, \quad 1 / 3 \leq x<2 / 3 \\
0, \quad x<0 \vee x \geq 1
\end{array}\right.
$$
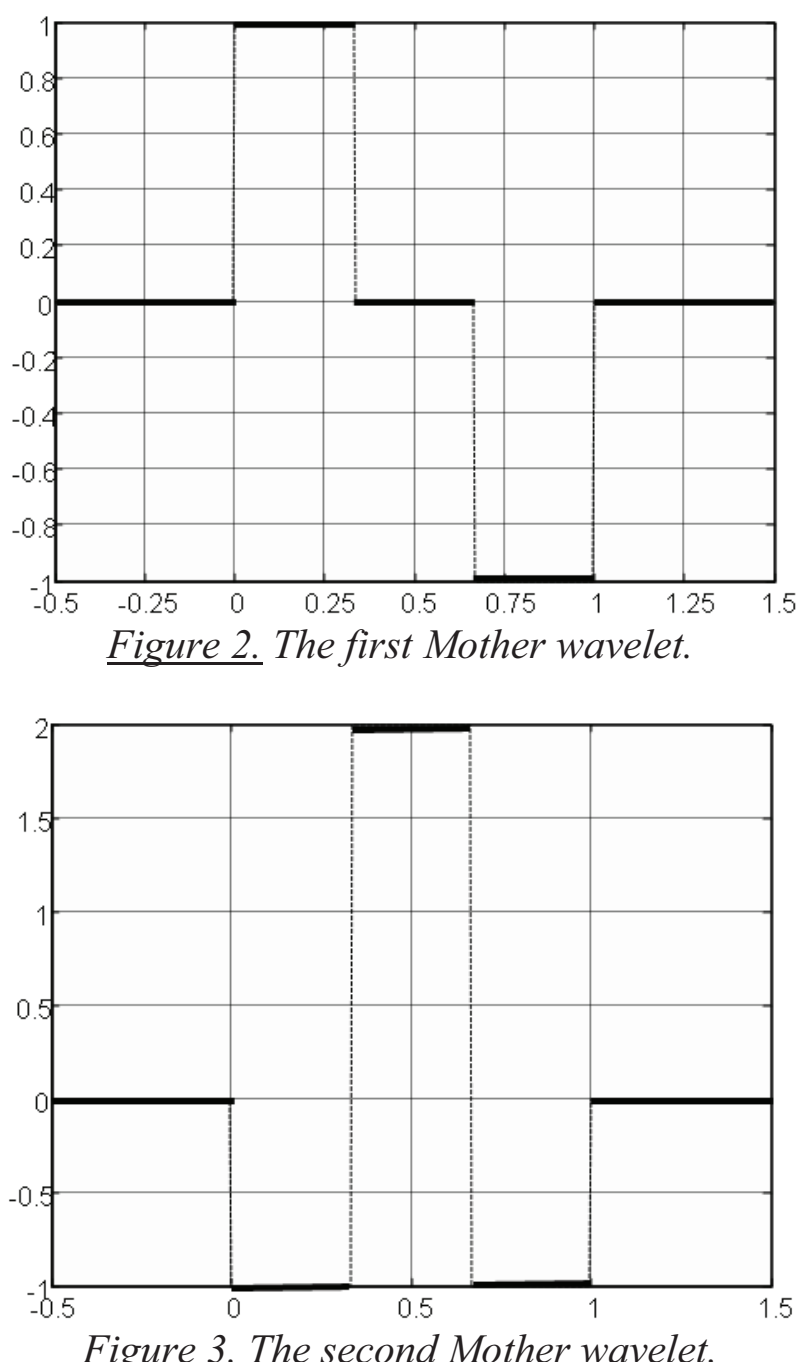

Matrix of transition from one level to the next level has the same structure as in the Haar basis [1-25]

$$
\left\lfloor\begin{array}{lll}
Q & & \\
& \ddots & \\
& & Q
\end{array}\right\rfloor
$$

where for the Haar basis we have 
About Wavelet-Based Multigrid Numerical Method of Structural Analysis with the Use of Discrete Haar Basis

$$
Q=\frac{1}{\sqrt{2}}\left\lfloor\begin{array}{cc}
1 & 1 \\
1 & -1
\end{array}\right\rfloor
$$

and for considering basis we have

$$
Q=\left[\begin{array}{ccc}
1 & 1 & -1 \\
1 & 0 & 2 \\
1 & -1 & -1
\end{array}\right]\left[\begin{array}{lll}
1 / \sqrt{3} & & \\
& 1 / \sqrt{2} & \\
& & 1 / \sqrt{6}
\end{array}\right] .
$$

Let us denote a family of discrete functions:

$$
\left\{\bar{\psi}_{j}^{p}\right\}, j=1,2, \ldots, N_{p}, \quad p=1, \ldots, M
$$

where $M$ is the number of levels; $N=3^{M}$ is space dimension,

$$
\begin{aligned}
& 1 \leq p<M: \quad \bar{\psi}_{j}^{p}=\left[\begin{array}{ll}
\bar{\psi}_{1, j}^{p} & \bar{\psi}_{2, j}^{p}
\end{array}\right], \\
& \psi_{1, j}^{p}(i)=\alpha_{1, p} \Psi_{1}\left(\frac{i-0.5}{3^{p}}-(j-1)\right) ; \\
& \psi_{2, j}^{p}(i)=\alpha_{2, p} \Psi_{2}\left(\frac{i-0.5}{3^{p}}-(j-1)\right) ; \\
& p=M: \quad \bar{\psi}_{1}^{M}=\left[\begin{array}{lll}
\bar{\psi}_{1,1}^{M} & \bar{\psi}_{2,1}^{M} & \bar{\phi}_{2,1}^{M}
\end{array}\right] ; \\
& \phi_{1}^{M}(i)=\alpha_{M} \Phi\left(\frac{i-0.5}{3^{M}}\right)
\end{aligned}
$$

$N_{p}=N / 3^{p}$ is the number of $\psi_{1, j}^{p}$ and $\psi_{2, j}^{p}$ at level number $p$;

$$
\alpha_{p}=\frac{1}{\sqrt{3^{p}}} ; \quad \alpha_{1, p}=\frac{1}{\sqrt{2^{p}}} ; \quad \alpha_{2, p}=\frac{1}{\sqrt{6^{p}}}
$$

are normalizing factors.

Because $1 / 3$ has no finite exact value, the expression

$$
\frac{i-0.5}{3^{p}}
$$

is used to evaluate correctly instead of

$$
\frac{i-1}{3^{p}} \text {. }
$$

The set $\left\{\bar{\psi}_{j}^{p}\right\}$ presented in this way is a basis in the $N$-dimensional vector space. Moreover, this basis will be orthonormal.

Let's consider a given vector

$$
\bar{u} \in R^{N}, \quad \bar{u}=\left\{u_{i}\right\}_{1 \leq i \leq N} .
$$

We present its decomposition in the Haar basis

$$
\bar{u}=\sum_{p=1}^{M}\left(\sum_{j=1}^{N_{p}}\left(v_{j}^{p} \overline{\psi 1}_{j}^{p}+w_{j}^{p} \bar{\psi} 2_{j}^{p}\right)+u_{1}^{M} \bar{\phi}_{1}^{M},\right.
$$

where we have

$$
\begin{aligned}
& v_{j}^{p}=\left(\bar{\psi}_{1, j}^{p}, \bar{u}\right) ; \quad w_{j}^{p}=\left(\bar{\psi}_{2, j}^{p}, \bar{u}\right) ; \\
& u_{1}^{M}=\left(\bar{\phi}_{1}^{M}, \bar{u}\right), \quad j=1,2, \ldots, N_{p}, \quad p=1, \ldots, M .
\end{aligned}
$$

\subsection{Determination of averaging coefficients.}

Let us consider an example of a grid partition for $N=9=3^{2}$, i.e. $M=2$. Then the location of nodes by levels can be represented as shown in Figure 4 . The formation of the decomposition coefficients at the first level is carried out according to the following formulas:

$$
\begin{gathered}
k=1,2,3 \\
u_{k}^{1}=\frac{1}{\sqrt{3}}\left(u_{3 k-2}^{0}+u_{3 k-1}^{0}+u_{3 k}^{0}\right)=\sqrt{3} \widetilde{u}_{k}^{0} ; \\
\widetilde{u}_{k}^{0}=\frac{1}{3}\left(u_{3 k-2}^{0}+u_{3 k-1}^{0}+u_{3 k}^{0}\right) \\
v_{k}^{1}=\frac{1}{\sqrt{2}}\left(u_{3 k-2}^{0}-u_{3 k}^{0}\right)= \\
=-\frac{1}{\sqrt{2}} 2 h \frac{u_{3 k}^{0}-u_{3 k-2}^{0}}{2 h}=-\sqrt{2} h\left(D_{0} u^{0}\right)_{3 k-1} \\
w_{k}^{1}=\frac{1}{\sqrt{6}}\left(-u_{3 k-2}^{0}+2 u_{3 k-1}^{0}-u_{3 k}^{0}\right)= \\
=-\frac{1}{\sqrt{6}} h^{2} \frac{\left.u_{3 k-2}^{0}-2 u_{3 k-1}^{0}+u_{3 k}^{0}\right)=}{h^{2}} \\
=-\frac{h^{2}}{\sqrt{6}}\left(D^{2} u^{0}\right)_{3 k-1} .
\end{gathered}
$$




\section{Zero level}

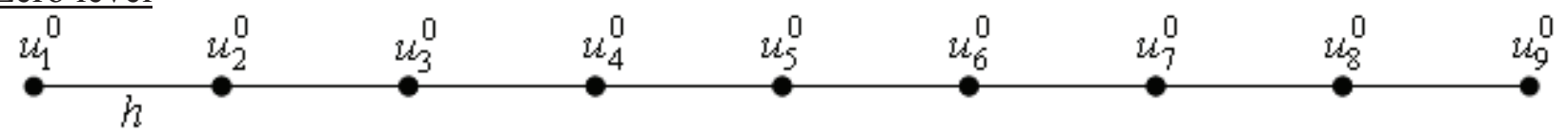

The first level

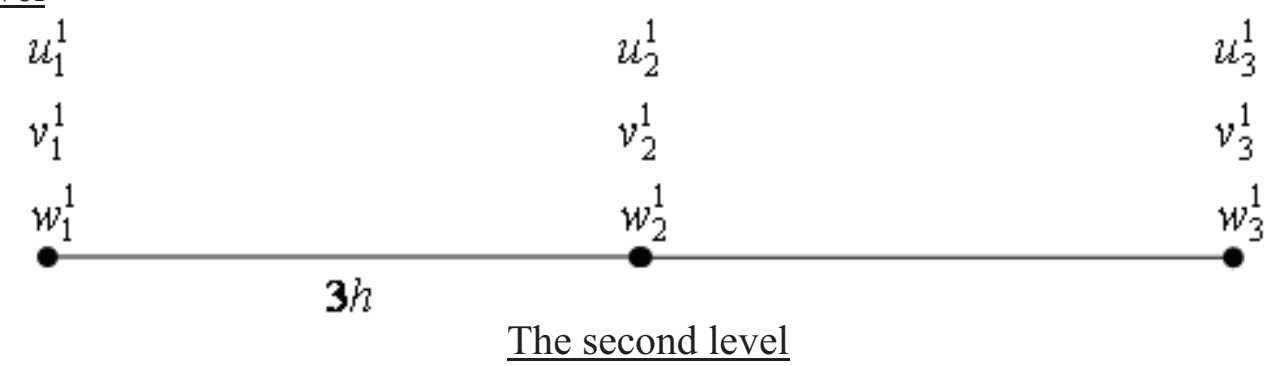

$$
\begin{aligned}
& u_{1}^{2} \\
& v_{1}^{2} \\
& w_{1}^{2}
\end{aligned}
$$

Figure 4. About determination of averaging coefficients.

The formation of the decomposition coefficients at the second level is carried out according to the following formulas:

$$
\begin{gathered}
u_{k}^{2}=\frac{1}{\sqrt{3}}\left(u_{1}^{1}+u_{2}^{1}+u_{3}^{1}\right) \\
v_{1}^{2}=\frac{1}{\sqrt{2}}\left(u_{1}^{1}-u_{3}^{1}\right)=-\frac{1}{\sqrt{2}} 6 h \frac{u_{3}^{1}-u_{1}^{1}}{6 h}= \\
=-\frac{\sqrt{3}}{\sqrt{2}} 6 h \frac{\tilde{u}_{3}^{0}-\widetilde{u}_{1}^{0}}{6 h}=-\frac{\sqrt{3}}{\sqrt{2}} 6 h\left(D_{0} \widetilde{u}^{0}\right)_{2} \\
w_{1}^{1}=\frac{1}{\sqrt{6}}\left(-u_{1}^{1}+2 u_{2}^{1}-u_{3}^{1}\right)= \\
\left.=-\frac{1}{\sqrt{6}}(3 h)^{2} \frac{u_{1}^{1}-2 u_{2}^{1}+u_{3}^{1}}{(3 h)^{2}}\right)= \\
\left.=-\frac{\sqrt{3}}{\sqrt{6}}(3 h)^{2} \frac{\widetilde{u}_{1}^{0}-2 \widetilde{u}_{2}^{0}+\widetilde{u}_{3}^{0}}{(3 h)^{2}}\right)= \\
=-\frac{(3 h)^{2}}{\sqrt{2}}\left(D^{2} \widetilde{u}^{0}\right)_{2} .
\end{gathered}
$$

For averaging (reduction) we assume

$$
\begin{aligned}
& \left(D_{0} u^{0}\right)_{3 k-1}=\left(D_{0} \widetilde{u}^{0}\right)_{2}, \\
& \quad\left(D^{2} u^{0}\right)_{3 k-1}=\left(D^{2} \widetilde{u}^{0}\right)_{2}, \quad k=1,2,3 .
\end{aligned}
$$

The following dependencies can be noted

$$
\begin{aligned}
& \left\{\begin{array}{l}
\left(D_{0} u^{0}\right)_{3 k-1}=-\frac{1}{\sqrt{2} h} v_{k}^{1} \\
\left(D^{2} u^{0}\right)_{3 k-1}=-\frac{\sqrt{6}}{h^{2}} w_{k}^{1} ;
\end{array}\right. \\
& \left\{\begin{array}{l}
\left(D_{0} \widetilde{u}^{0}\right)_{2}=-\frac{\sqrt{2}}{\sqrt{3} \cdot 6 h} v_{1}^{2} \\
\left(D^{2} \widetilde{u}^{0}\right)_{2}=-\frac{\sqrt{2}}{(3 h)^{2}} w_{1}^{2} ;
\end{array}\right.
\end{aligned}
$$

and then we have

$$
\left\{\begin{array}{l}
v_{k}^{1}=\frac{1}{3 \sqrt{3}} v_{1}^{2} \\
w_{k}^{1}=\frac{1}{3^{2} \sqrt{3}} w_{1}^{2},
\end{array} \quad k=1,2,3 .\right.
$$

\subsection{The final formulas.}

Let the initial one-dimensional domain be given as interval with length $L$. We can use simple mesh (grid) for approximation of domain and divide interval (the initial domain) into $(N-1)$ equal parts. We can represent the mesh vector function $\bar{u}=\left[\begin{array}{lll}u_{1} & \ldots & u_{N}\end{array}\right]^{T}$ in the form 


$$
\bar{u}=\sum_{j=1}^{N_{0}} u_{j}^{0} \bar{\Phi}_{j}^{0}
$$

where we have

$$
\begin{gathered}
N_{0}=N=3^{M} ; \\
u_{j}^{0}=u_{j}, \quad 1 \leq j \leq N ; \\
\bar{\Phi}_{j}^{0}(i)= \begin{cases}1, & i=j \\
0, & i \neq j\end{cases}
\end{gathered}
$$

$-j$-th vector of unit basis of level 0 ,

$$
1 \leq j \leq N_{0}=N, \quad 1 \leq i \leq N
$$

At the same time, this grid function can be represented in the basis of the first level as

$$
\bar{u}=\sum_{j=1}^{N_{1}} u_{j}^{1} \bar{\Phi}_{j}^{1}+\sum_{j=1}^{N_{1}} v_{j}^{1} \bar{\Psi}_{1, j}^{1}+\sum_{j=1}^{N_{1}} w_{j}^{1} \bar{\Psi}_{2, j}^{1},
$$

where we have

$$
\begin{gathered}
N_{1}=N / 3 ; \\
u_{j}^{1}=\left(\bar{u}, \bar{\Phi}_{j}^{1}\right) ; \quad v_{j}^{1}=\left(\bar{u}, \bar{\Psi}_{j}^{1}\right) ; \\
w_{j}^{1}=\left(\bar{u}, \bar{\Psi}_{2, j}^{1}\right), \quad 1 \leq j \leq N_{1}, \\
\bar{u}^{1}=\left[u_{1}^{1} \ldots u_{N_{1}}^{1}\right]^{\mathrm{T}}, \quad \bar{v}^{1}=\left[v_{1}^{1} \ldots v_{N_{1}}^{1}\right]^{\mathrm{T}}, \\
\bar{w}^{1}=\left[w_{1}^{1} \ldots w_{N_{1}}^{1}\right]^{\mathrm{T}} . \\
\bar{\Phi}_{j}^{1}=\alpha\left(\bar{\Phi}_{3 j-2}^{0}+\bar{\Phi}_{3 j-1}^{0}+\bar{\Phi}_{3 j}^{0}\right)
\end{gathered}
$$

is the $j$-th approximation vector of discrete wavelet basis of the first level, $1 \leq j \leq N_{1}$;

$$
\bar{\Psi}_{1, j}^{1}=\alpha_{1}\left(\bar{\Phi}_{3 j-2}^{0}-\bar{\Phi}_{3 j}^{0}\right)
$$

is the $j$-th refinement vector of discrete wavelet basis of the first level, $1 \leq j \leq N_{1}$;

$$
\bar{\Psi}_{2, j}^{1}=\alpha_{2}\left(-\bar{\Phi}_{3 j-2}^{0}+2 \bar{\Phi}_{3 j-1}^{0}-\bar{\Phi}_{3 j}^{0}\right)
$$

is the $j$-th refinement vector of discrete wavelet basis of the first level, $1 \leq j \leq N_{1}$;

$$
\left\{\begin{array}{l}
\alpha=1 / \sqrt{3} \\
\alpha_{1}=1 / \sqrt{2} \\
\alpha_{2}=1 / \sqrt{6}
\end{array}\right.
$$

are normalizing factors.

Based on the representation of (1.28), the mesh function is represented as a sum, where the first term is its approximation on the mesh (grid) of the first level, consisting of $N_{1}$ nodes, and the second and third terms are called refinement (addition to the initial state) on the mesh (grid) of the first level.

The representation (1.28) can be written as

$$
\begin{gathered}
\bar{u}=\bar{u}_{1}^{0}+\bar{v}_{1}^{0}+\bar{w}_{1}^{0} \\
\bar{u}_{1}^{0}=\sum_{j=1}^{N_{1}} u_{j}^{1} \bar{\Phi}_{j}^{1}=\Phi_{1} \Phi_{1}^{T} \bar{u}=\Phi_{1} \bar{u}^{1} \\
\bar{v}_{1}^{0}=\sum_{j=1}^{N_{1}} v_{j}^{1} \bar{\Psi}_{1, j}^{1}=\Psi_{1,1} \Psi_{1,1}^{T} \bar{u}=\Psi_{1,1} \bar{v}^{1} \\
\bar{w}_{1}^{0}=\sum_{j=1}^{N_{1}} w_{j}^{1} \bar{\Psi}_{2, j}^{1}=\Psi_{2,1} \Psi_{2,1}^{T} \bar{u}=\Psi_{2,1} \bar{w}^{1}
\end{gathered}
$$

where we have

$$
\begin{aligned}
\Phi_{1} & =\left[\begin{array}{lll}
\bar{\Phi}_{1}^{1} & \ldots & \bar{\Phi}_{N_{1}}^{1}
\end{array}\right] ; \\
\Psi_{1,1} & =\left[\begin{array}{lll}
\bar{\Psi}_{1,1}^{1} & \ldots & \bar{\Psi}_{1, N_{1}}^{1}
\end{array}\right] ; \\
\Psi_{2,1} & =\left[\begin{array}{lll}
\bar{\Psi}_{2,1}^{1} & \ldots & \Psi_{2, N_{1}}^{1}
\end{array}\right]
\end{aligned}
$$

matrices of size $N \times N_{1}$, the columns of which are respectively approximation and refinement vectors of the discrete basis of the first level.

Due to the orthonormality of the Haar basis [17,9-25], the operators

$P_{\Phi}=\Phi_{1} \Phi_{1}^{T}, \quad P_{\Psi, 1}=\Psi_{1,1} \Psi_{1,1}^{T}, \quad P_{\Psi, 2}=\Psi_{2,1} \Psi_{2,1}^{T}$ 
are projectors of the space of vector functions of the original mesh (grid) to the space of their approximation on the first-level grid and its complement (the refining component) to the initial state, respectively.

spectively.

\subsection{Basic scheme of the two-grid method.}

Let systems of linear algebraic equations

$$
A \bar{u}=\bar{f}
$$

are discrete analogs of some operator equation defined on a given interval of order $N$.

We can substitute in (1.43) the expression for $\bar{u}$ in the form (1.35). Then we can multiply, in turn, both sides of the equality on the left by the matrices $\Phi_{1}^{T}$ and $\Psi_{1,1}^{T}, \Psi_{2,1}^{T}$. Thus we have

$$
\begin{gathered}
\Phi_{1}^{T} A \Phi_{1} \bar{u}^{1}+\Phi_{1}^{T} A \Psi_{1,1} \bar{v}^{1}+ \\
+\Phi_{1}^{T} A \Psi_{2,1} \bar{w}^{1}=\Phi_{1}^{T} \bar{f} \\
\Psi_{1,1}^{T} A \Phi_{1} \bar{u}^{1}+\Psi_{1,1}^{T} A \Psi_{1,1} \bar{v}^{1}+ \\
+\Psi_{1,1}^{T} A \Psi_{2,1} \bar{w}^{1}=\Psi_{1,1}^{T} \bar{f} \\
\Psi_{2,1}^{T} A \Phi_{1} \bar{u}^{1}+\Psi_{2,1}^{T} A \Psi_{1,1} \bar{v}^{1}+ \\
+\Psi_{2,1}^{T} A \Psi_{2,1} \bar{w}^{1}=\Psi_{2,1}^{T} \bar{f}
\end{gathered}
$$

or

$$
\begin{aligned}
& A_{1,1} \bar{u}^{1}+A_{1,2} \bar{v}^{1}+A_{1,3} \bar{w}^{1}=\bar{f}_{u} \\
& A_{2,1} \bar{u}^{1}+A_{2,2} \bar{v}^{1}+A_{2,3} \bar{w}^{1}=\bar{f}_{v} \\
& A_{3,1} \bar{u}^{1}+A_{3,2} \bar{v}^{1}+A_{3,3} \bar{w}^{1}=\bar{f}_{w},
\end{aligned}
$$

where we have

$$
\begin{gathered}
A_{1,1}=\Phi_{1}^{T} A \Phi_{1} ; \quad A_{1,2}=\Phi_{1}^{T} A \Psi_{1,1} \\
A_{1,3}=\Phi_{1}^{T} A \Psi_{2,1} ; \quad A_{2,1}=\Psi_{1,1}^{T} A \Phi_{1} ; \\
A_{2,2}=\Psi_{1,1}^{T} A \Psi_{1,1} ; \quad A_{2,3}=\Psi_{1,1}^{T} A \Psi_{2,1} \\
A_{3,1}=\Psi_{2,1}^{T} A \Phi_{1} ; \quad A_{3,2}=\Psi_{2,1}^{T} A \Psi_{1,1} \\
A_{3,3}=\Psi_{2,1}^{T} A \Psi_{2,1}
\end{gathered}
$$

are block matrices of size $N_{1} \times N_{1}$.

$$
\bar{f}_{u}=\Phi_{1}^{T} \bar{f} ; \quad \bar{f}_{v}=\Psi_{1,1}^{T} \bar{f} ; \quad \bar{f}_{w}=\Psi_{2,1}^{T} \bar{f}
$$

are right-side vectors of length $N_{1}$.

We can find the solution of the system (1.45) using the block Gaussian method.

The expanded block matrix has the form:

$$
\left[\begin{array}{ccc|c}
A_{1,1} & A_{1,2} & A_{1,3} & \bar{f}_{u} \\
A_{2,1} & A_{2,2} & A_{2,3} & \bar{f}_{v} \\
A_{3,1} & A_{3,2} & A_{3,3} & \bar{f}_{w}
\end{array}\right] .
$$

We have the following result of forward algorithm:

- the first step

$$
\left[\begin{array}{ccc|c}
A_{11} & A_{12} & A_{13} & \bar{f}_{u} \\
0 & A_{22}^{1} & A_{23}^{1} & \bar{f}_{v}^{1} \\
0 & A_{32}^{1} & A_{33}^{1} & \bar{f}_{w}^{1}
\end{array}\right],
$$

where we have

$$
\begin{aligned}
A_{2,2}^{1}= & A_{2,2}-C_{2,1} A_{1,2} ; \quad A_{2,3}^{1}=A_{2,3}-C_{2,1} A_{1,3} ; \\
& \bar{f}_{v}^{1}=\bar{f}_{v}-C_{2,1} \bar{f}_{u} ; \quad C_{2,1}=A_{2,1} A_{1,1}^{-1} ; \\
A_{3,2}^{1}= & A_{3,2}-C_{3,1} A_{1,2} ; \quad A_{3,3}^{1}=A_{3,3}-C_{3,1} A_{1,3} ;
\end{aligned}
$$

$$
\bar{f}_{w}^{1}=\bar{f}_{w}-C_{3,1} \bar{f}_{u}, \quad C_{3,1}=A_{3,1} A_{1,1}^{-1} .
$$

- the second step

$$
\left[\begin{array}{ccc|c}
A_{1,1} & A_{1,2} & A_{1,3} & \bar{f}_{u} \\
0 & A_{2,2}^{1} & A_{2,3}^{1} & \bar{f}_{v}^{1} \\
0 & 0 & A_{3,3}^{2} & \bar{f}_{w}^{2}
\end{array}\right],
$$

where we have

$$
\begin{gathered}
A_{3,3}^{2}=A_{3,3}^{1}-C_{3,2} A_{2,3}^{2} ; \\
\bar{f}_{w}^{2}=\bar{f}_{w}^{1}-C_{3,2} \bar{f}_{v}^{1}, \quad C_{3,2}=A_{3,2}^{1}\left(A_{2,2}^{1}\right)^{-1} .
\end{gathered}
$$

We have the following result of backward algorithm 


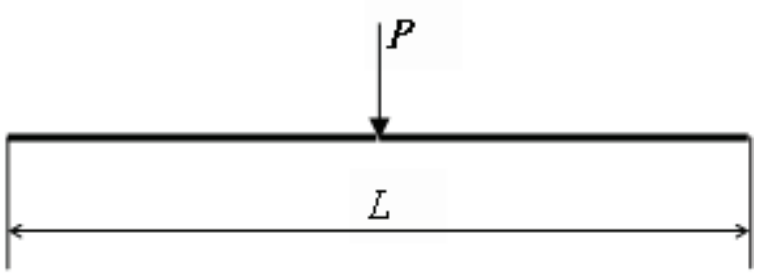

Figure 5. To the formulation of the boundary problem.

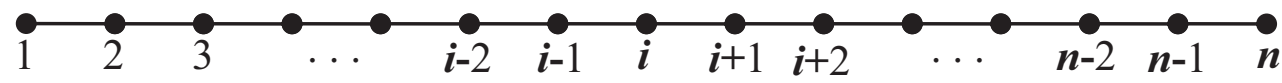

Figure 6. Discrete approximation of the domain.

$$
\begin{aligned}
& \bar{w}^{1}=\left(A_{3,3}^{2}\right)^{-1} \bar{f}_{w}^{2} \\
& \bar{v}^{1}=\left(A_{2,2}^{1}\right)^{-1}\left(\bar{f}_{v}^{1}-A_{2,3}^{1} \bar{v}^{1}\right) \\
& \bar{u}^{1}=A_{1,1}^{-1}\left(\bar{f}_{u}-A_{1,2} \bar{v}^{1}-A_{1,3} \bar{w}^{1}\right) .
\end{aligned}
$$

In accordance with formulas (1.35)-(1.38) solution of the considering problem (1.43) has the form

$$
\bar{u}=\Phi_{1} \bar{u}^{1}+\Psi_{1,1} \bar{v}^{1}+\Psi_{2,1} \bar{w}^{1}
$$

It should be noted that the proposed method makes it possible to obtain a solution with the use of matrices of size $N_{1}=N / 3$ and vectors of size $N_{1}=N / 3$.

\subsection{Numerical sample.}

Let us consider (as a model example) the numerical solution of the boundary problem of the bending of a beam on an elastic foundation with the following parameters: $L=8 \mathrm{~m}$ is the length of the beam; $h=1.3 \mathrm{~m}$ is the height of the cross section of the beam; $b=1 \mathrm{~m}$ is the width of the cross section of the beam; $E=2560 \cdot 10^{4} \mathrm{kN} / \mathrm{m}^{2}$ is the modulus of elasticity; $P=100 \mathrm{kN}$ is the load set at the middle point, $P_{h}=100 / h_{b}$; $k=75 \cdot 10^{3} \mathrm{kN} / \mathrm{m}^{3}$ is the coefficient characterizing the resistance of the foundation in the model of Winkler; $\bar{k}=k \cdot b, J=b h^{3} / 12$ (Figure 5). The definition of the deflection of the Bernoulli beam is reduced to the solution of the following boundary problem:

$$
\begin{gathered}
y^{(4)}(x)+4 \alpha^{4} y(x)=F(x), \quad 0<x<L ; \\
\left\{\begin{array}{l}
y(0)=y^{\prime \prime}(0)=0 \\
y(L)=y^{\prime \prime}(L)=0
\end{array}\right.
\end{gathered}
$$

where we have

$$
4 \alpha^{4}=\frac{\bar{k}}{E J} ; \quad F=\frac{P}{E J} \delta\left(x-\frac{L}{2}\right) .
$$

Let us divide the interval $(0, L)$ into equal parts with step (Figure 6).

If $n$ is the total number of points, it is obvious that

$$
h_{b}=L /(n-1) .
$$

Next, we move from the solution of the boundary problem (1.63)-(1.64) to the solution of the following system of difference equations:

$$
\begin{aligned}
& i=1: \quad y_{1}=f_{1} \\
& i=2:-2 y_{1}+\left(5+4 h_{b}^{4} \alpha^{4}\right) y_{2}-4 y_{3}+y_{4}=f_{2} \\
& 2<i<n-1: \quad y_{i-2}-4 y_{i-1}+\left(6+4 h_{b}^{4} \alpha^{4}\right) y_{i}- \\
& -4 y_{i+1}+y_{i+2}=f_{i} \\
& i=n-1: \quad y_{n-3}-4 y_{n-2}+\left(5+4 h_{b}^{4} \alpha^{4}\right) y_{n-1}- \\
& -2 y_{n}=f_{n-1} \\
& i=n: y_{n}=f_{n},
\end{aligned}
$$

where we have 


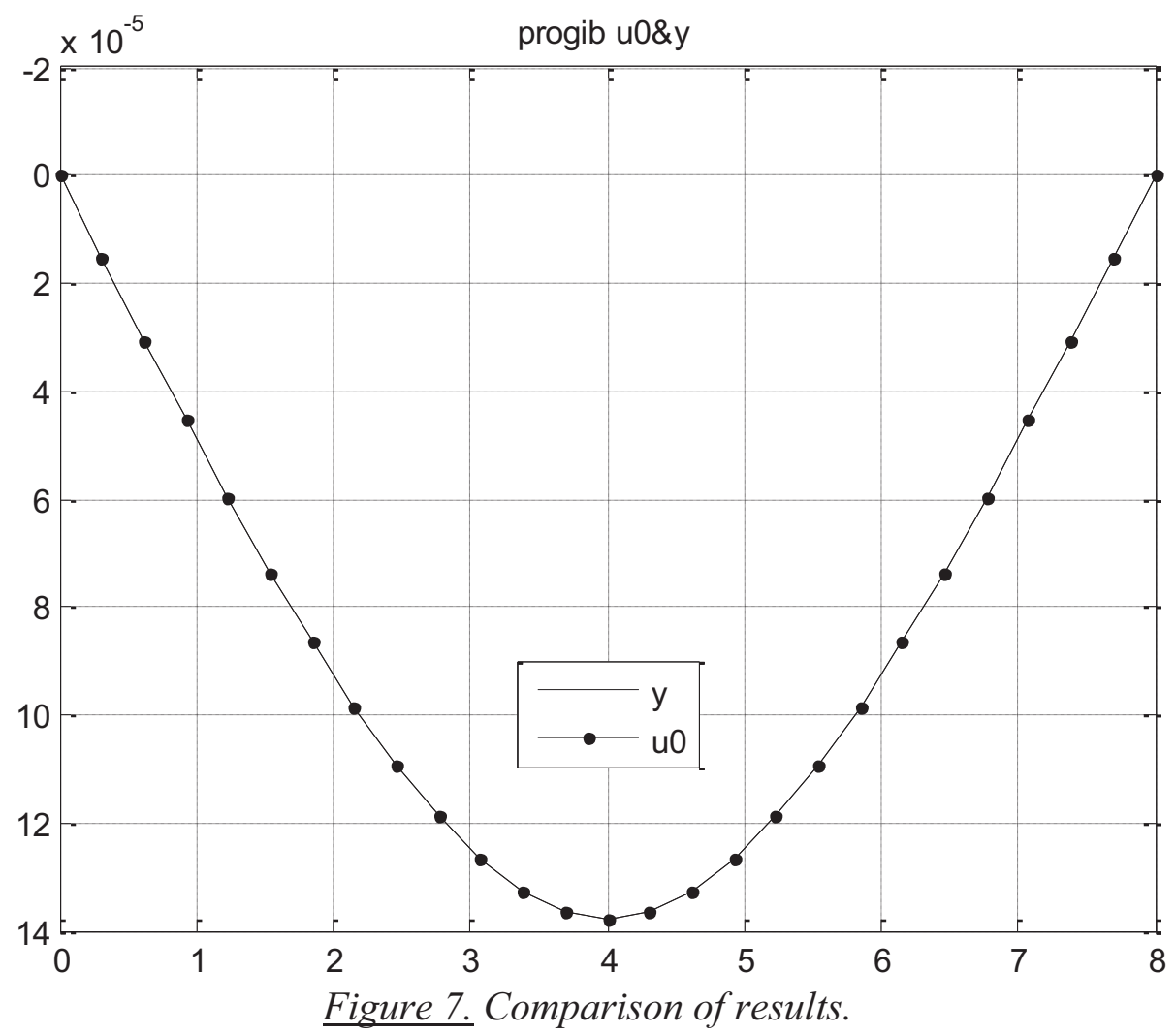

$$
\begin{aligned}
& x_{i}=h_{b}(i-1) ; \quad y_{i}=y\left(x_{i}\right) ; \\
f_{i}= & \left\{\begin{array}{l}
0, \quad i=1 \\
h_{b}^{4}\left[F\left(x_{i}\right) / h_{b}\right], \quad 2 \leq i \leq n-1 \\
0, \quad i=n .
\end{array}\right.
\end{aligned}
$$

In accordance with the results of analysis comparative graphs of deflections were obtained. Direct solution of the system (1.67) and solution defined by the formula (1.62) are presented at Figure 7. It should be noted that full match results obtained.

\section{TWO-DIMENSIONAL PROBLEMS}

\subsection{General information.}

Let the initial two-dimensional domain be given as a rectangle [8]. Let $L_{1}$ and $L_{2}$ be lengths of sides of this rectangle in directions corresponding to Cartesian coordinates $x_{1}$ and $x_{2}$. We can use simple rectangular mesh (grid) for approximation of domain and divide each side of the rectangle (the initial domain) into $(N-1)$ equal parts. The corresponding mesh (grid) width are defined by formulas

$$
h_{1}=L_{1} /(N-1) ; \quad h_{2}=L_{2} /(N-1) \text {. }
$$

Thus, the resulting mesh contains $N^{2}$ nodes.

Let us introduce the mesh function

$$
\bar{u}=\left[\begin{array}{lllllll}
u_{1,1} & \ldots & u_{1, N} & \ldots & u_{N, 1} & \ldots & u_{N, N}
\end{array}\right]^{T} .
$$

We can represent the mesh function (1.2) in the form

$$
\bar{u}=\sum_{j_{2}=1}^{N_{0}} \sum_{j_{1}=1}^{N_{0}} u_{j_{2}, j_{1}}^{0} \bar{\Phi}_{j_{2}, j_{1}}^{0},
$$

where we have

$$
\begin{gathered}
N_{0}=N ; \\
u_{j_{2}, j_{1}}^{0}=u_{j_{2}, j_{1}}, \quad 1 \leq j_{1}, j_{2} \leq N ;
\end{gathered}
$$




$$
\begin{gathered}
\bar{\Phi}_{j_{2}, j_{1}}^{0}\left(i_{2}, i_{1}\right)=\left\{\begin{array}{l}
1, \quad i_{1}=j_{1} \wedge i_{2}=j_{2} \\
0, \neg\left(i_{1}=j_{1} \wedge i_{2}=j_{2}\right)
\end{array}\right. \\
1 \leq j_{2}, j_{1} \leq N_{0}=N, \quad 1 \leq i_{2}, i_{1} \leq N,
\end{gathered}
$$

where $\bar{\Phi}_{j_{2}, j_{1}}^{0}$ is $\left(j_{2}, j_{1}\right)$-th vector of a unit basis or a discrete zero-level Haar basis

The mesh function (2) can also be represented in the form of an expansion in the Haar basis of the first level:

$$
\begin{aligned}
\bar{u} & =\sum_{j_{2}=1}^{N_{1}} \sum_{j_{1}=1}^{N_{1}} u_{j_{2}, j_{1}}^{1} \bar{\Phi}_{j_{2}, j_{1}}^{1}+\sum_{j_{2}=1}^{N_{1}} \sum_{j_{1}=1}^{N_{1}} v_{1, j_{2}, j_{1}}^{1} \bar{\Psi}_{1, j_{2}, j_{1}}^{1}+ \\
& +\sum_{j_{2}=1}^{N_{1}=1} \sum_{j_{1}=1}^{N_{1}} v_{2, j_{2}, j_{1}}^{1} \bar{\Psi}_{2, j_{2}, j_{1}}^{1}+\sum_{j_{2}=1}^{N_{1}} \sum_{j_{1}=1}^{N_{1}} v_{3, j_{2}, j_{1}}^{1} \bar{\Psi}_{3, j_{2}, j_{1}}^{1},
\end{aligned}
$$

where we have

$$
\begin{aligned}
& N_{1}=N / 2 \text {; } \\
& u_{j_{2}, j_{1}}^{1}=\left(\bar{u}, \bar{\Phi}_{j_{2}, j_{1}}^{1}\right) ; \quad v_{1, j_{2}, j_{1}}^{1}=\left(\bar{u}, \bar{\Psi}_{1, j_{2}, j_{1}}^{1}\right) \text {, } \\
& v_{2, j_{2}, j_{1}}^{1}=\left(\bar{u}, \bar{\Psi}_{2, j_{2}, j_{1}}^{1}\right) ; v_{3, j_{2}, j_{1}}^{1}=\left(\bar{u}, \bar{\Psi}_{3, j_{2}, j_{1}}^{1}\right) \text {; } \\
& \bar{u}^{1}=\left[\begin{array}{llllll}
u_{1,1}^{1} \ldots & u_{1, N_{1}}^{1} \ldots & u_{N_{1}, 1}^{1} \ldots & u_{N_{1}, N_{1}}^{1}
\end{array}\right]^{T} ; \\
& \bar{v}_{k}^{1}=\left[v_{k, 1,1}^{1} \ldots v_{k, 1, N_{1}}^{1}, \ldots v_{k, N_{1}, 1}^{1} \ldots{ }_{k, N_{1}, N_{1}}^{1}\right]^{T}, k=1,2,3 \text {; } \\
& \bar{\Phi}_{j_{2}, j_{1}}^{1}=\alpha\left(\bar{\Phi}_{2 j_{2}-1,2 j_{1}-1}^{0}+\bar{\Phi}_{2 j_{2}-1,2 j_{1}}^{0}+\right. \\
& \left.+\bar{\Phi}_{2 j_{2}, 2 j_{1}-1}^{0}+\bar{\Phi}_{2 j_{2}, 2 j_{1}}^{0}\right)
\end{aligned}
$$

- $\left(j_{2}, j_{1}\right)$ - th approximating vector of the discrete Haar basis of the first level, $1 \leq j_{2}, j_{1} \leq N_{1}$;

$$
\begin{gathered}
\bar{\Psi}_{1, j_{2}, j_{1}}^{1}=\alpha\left(\bar{\Phi}_{2 j_{2}-1,2 j_{1}-1}^{0}-\bar{\Phi}_{2 j_{2}-1,2 j_{1}}^{0}+\right. \\
\left.+\bar{\Phi}_{2 j_{2}, 2 j_{1}-1}^{0}-\bar{\Phi}_{2 j_{2}, 2 j_{1}}^{0}\right)
\end{gathered}
$$

- $\left(1, j_{2}, j_{1}\right)$ - th refining vector of the discrete Haar basis of the first level,

$$
\begin{gathered}
\bar{\Psi}_{2, j_{2}, j_{1}}^{1}=\alpha\left(\bar{\Phi}_{2 j_{2}-1,2 j_{1}-1}^{0}+\bar{\Phi}_{2 j_{2}-1,2 j_{1}}^{0}-\right. \\
\left.-\bar{\Phi}_{2 j_{2}, 2 j_{1}-1}^{0}-\bar{\Phi}_{2 j_{2}, 2 j_{1}}^{0}\right)
\end{gathered}
$$

- $\left(2, j_{2}, j_{1}\right)$-th refining vector of the discrete Haar basis of the first level,

$$
\begin{gathered}
\bar{\Psi}_{3, j_{2}, j_{1}}^{1}=\alpha\left(\bar{\Phi}_{2 j_{2}-1,2 j_{1}-1}^{0}-\bar{\Phi}_{2 j_{2}-1,2 j_{1}}^{0}-\right. \\
\left.-\bar{\Phi}_{2 j_{2}, 2 j_{1}-1}^{0}+\bar{\Phi}_{2 j_{2}, 2 j_{1}}^{0}\right)
\end{gathered}
$$

$-\left(3, j_{2}, j_{1}\right)$ - th refining vector of the discrete

Haar basis of the first level,

$$
1 \leq j_{2}, j_{1} \leq N_{1}
$$

$\alpha=1 / 2$ is normalizing factor.

In accordance with (2.7), the mesh function $\bar{u}$ is represented as a sum in which the first summand (the first sum) is its approximation on the grid of the first level including $N_{1}^{2}$ nodes, and other three terms are called the refinement (the complement to the initial state) on the grid the first level. The representation (2.7) can be written in the form

$$
\begin{gathered}
\bar{u}=\bar{u}_{1}^{0}+\bar{v}_{1,1}^{0}+\bar{v}_{2,1}^{0}+\bar{v}_{3,1}^{0} ; \\
\bar{u}_{1}^{0}=\sum_{j_{2}=1}^{N_{1}} \sum_{j_{1}=1}^{N_{1}} u_{j_{2}, j_{1}}^{1} \bar{\Phi}_{j_{2}, j_{1}}^{1}=\Phi_{1} \Phi_{1}^{T} \bar{u}=\Phi_{1} \bar{u}^{1} ;(2.19) \\
\bar{v}_{k, 1}^{0}=\sum_{j_{2}=1}^{N_{1}} \sum_{j_{1}=1}^{N_{1}} v_{k, j_{2}, j_{1}}^{1} \bar{\Psi}_{k, j_{2}, j_{1}}^{1}=\Psi_{k, 1} \Psi_{k, 1}^{T} \bar{u}=\Psi_{k, 1} \bar{v}_{k}^{1}, \\
k=1,2,3,
\end{gathered}
$$

where we have

$$
\begin{gathered}
\Phi_{1}=\left[\bar{\Phi}_{1,1}^{1} \ldots \bar{\Phi}_{1, N_{1}}^{1}, . . \bar{\Phi}_{N_{1}, 1}^{1} \ldots \bar{\Phi}_{N_{1}, N_{1}}^{1}\right] \\
\Psi_{k, 1}=\left[\bar{\Psi}_{k, 1,1}^{1} \ldots \bar{\Psi}_{k, 1, N_{1}}^{1} \ldots \bar{\Psi}_{k, N_{1}, 1}^{1} \ldots \bar{\Psi}_{k, N_{1}, N_{1}}^{1}\right] \\
k=1,2,3
\end{gathered}
$$

are matrices of size $N^{2} \times N_{1}^{2}$, whose columns are, respectively, approximating and detailing vectors of the discrete Haar basis of the first level.

Due to the orthonormality of the Haar basis [17,9-25], the operators

$$
P_{\Phi}=\Phi_{1} \Phi_{1}^{T}, \quad P_{\Psi, k}=\Psi_{k, 1} \Psi_{k, 1}^{T}, \quad k=1,2,3
$$

are projectors of the space of vector functions of the original grid to the space of their approxima- 
tion on the first-level grid and its complement (the refining component) to the initial state, respectively.

\subsection{Basic scheme of the two-grid method.}

Let systems of linear algebraic equations

$$
A \bar{u}=\bar{f}
$$

are discrete analogs of some operator equation defined on a given rectangular prism of order $N^{2}$.

We can substitute in (2.24) the expression for $\bar{u}$ in the form (2.18). Then we can multiply, in turn, both sides of the equality on the left by the matrices $\Phi_{1}^{T}$ and $\Psi_{k, 1}^{T}, k=1,2,3$. Thus we have

$$
\begin{aligned}
& \Phi_{1}^{T} A \Phi_{1} \bar{u}^{1}+\sum_{k=1}^{3} \Phi_{1}^{T} A \Psi_{k 1} \bar{v}_{k}^{1}=\Phi_{1}^{T} \bar{f} \\
& \Psi_{1,1}^{T} A \Phi_{1} \bar{u}^{1}+\sum_{k=1}^{3} \Psi_{1,1}^{T} A \Psi_{k, 1} \bar{v}_{k}^{1}=\Psi_{1,1}^{T} \bar{f} \\
& \Psi_{2,1}^{T} A \Phi_{1} \bar{u}^{1}+\sum_{k=1}^{3} \Psi_{2,1}^{T} A \Psi_{k, 1} \bar{v}_{k}^{1}=\Psi_{2,1}^{T} \bar{f} \\
& \Psi_{3,1}^{T} A \Phi_{1} \bar{u}^{1}+\sum_{k=1}^{3} \Psi_{3,1}^{T} A \Psi_{k, 1} \bar{v}_{k}^{1}=\Psi_{3,1}^{T} \bar{f}
\end{aligned}
$$

Equations (2.25) can be rewritten in the form

$$
\sum_{i=1}^{4} A_{i, j} \bar{w}_{j}=\bar{f}_{i}, \quad i=1, \ldots, 4
$$

where $A_{i, j}$ are block matrices of size $N_{1}^{2} \times N_{1}^{2}$; $\bar{f}_{i}$ and $\bar{w}_{j}$ are block vectors of size $N_{1}^{2}$,

$$
\begin{gathered}
A_{1,1}=\Phi_{1}^{T} A \Phi_{1} ; \quad A_{1, k+1}=\Phi_{1}^{T} A \Psi_{k, 1}, \\
A_{k+1,1}=\Psi_{k, 1}^{T} A \Phi_{1}, \quad k=1,2,3 ; \\
A_{k+1, p+1}=\Psi_{k, 1}^{T} A \Psi_{p+1}, \quad k, p=1,2,3 ; \\
\bar{f}_{1}=\Phi_{1}^{T} \bar{f}, \quad \bar{f}_{k+1}=\Psi_{k, 1}^{T} \bar{f}, \quad k=1, \ldots, 7 \\
\bar{w}_{1}=\bar{u}^{1}, \quad \bar{w}_{k+1}=v_{k}^{1}, \quad k=1, \ldots, 7
\end{gathered}
$$

We can find the solution of the system (2.26) using the block Gaussian method.

The expanded block matrix has the form:

$$
\left[\begin{array}{cccc|c}
A_{1,1} & A_{1,2} & A_{1,3} & A_{1,4} & \bar{f}_{1} \\
A_{2,1} & A_{2,2} & A_{2,3} & A_{2,4} & \bar{f}_{2} \\
A_{3,1} & A_{3,2} & A_{3,3} & A_{3,4} & \bar{f}_{3} \\
A_{4,1} & A_{4,2} & A_{4,3} & A_{4,4} & \bar{f}_{4}
\end{array}\right] .
$$

We have the following result of forward algorithm:

$$
\left[\begin{array}{cccc|c}
A_{1,1} & A_{1,2} & A_{1,3} & A_{1,4} & \bar{f}_{1} \\
0 & A_{2,2}^{1} & A_{2,3}^{1} & A_{2,4}^{1} & \bar{f}_{2}^{1} \\
0 & 0 & A_{3,3}^{2} & A_{3,4}^{2} & \bar{f}_{3}^{2} \\
0 & 0 & 0 & A_{4,4}^{3} & \bar{f}_{4}^{3}
\end{array}\right],
$$

where we have

$$
\begin{array}{r}
A_{i, j}^{k}=A_{i, j}^{k-1}-C_{i, k} A_{k, j}^{k-1}, \quad k=1, \ldots, 4, \\
i=k+1, \ldots, 4, \quad j=k+1, \ldots, 4 ; \\
\bar{f}_{i}^{k}=\bar{f}_{i}^{k-1}-C_{i, k} \bar{f}_{k}^{k-1}, \quad k=1, \ldots, 4, \\
i=k+1, \ldots, 4 ; \\
C_{i, k}=A_{i, k}^{k-1}\left(A_{k, k}^{k-1}\right)^{-1}, \quad k=1, \ldots, 3, \\
i=k+1, \ldots, 4 .
\end{array}
$$

We have the following result of backward algorithm

$$
\bar{w}_{8}=\left(A_{4,4}^{3}\right)^{-1} \bar{f}_{4}^{3} ;
$$

$\bar{w}_{i}=\left(A_{i, i}^{i-1}\right)^{-1}\left(\bar{f}_{i}^{i-1}-\sum_{j=i+1}^{4} A_{i, i}^{i-1} \bar{w}_{j}\right), i=3,2,1$.

In accordance with formulas (2.18)-(2.20) solution of the considering problem (2.24) has the form

$$
\begin{aligned}
\bar{u} & =\bar{u}_{1}^{0}+\sum_{k=1}^{7} \bar{v}_{k, 1}^{0}= \\
& =\Phi_{1} \bar{u}^{1}+\sum_{k=1}^{7} \Psi_{k, 1} \bar{v}_{k}^{1}=\Phi_{1} \bar{w}_{1}+\sum_{k=1}^{7} \Psi_{k, 1} \bar{w}_{k+1} .
\end{aligned}
$$




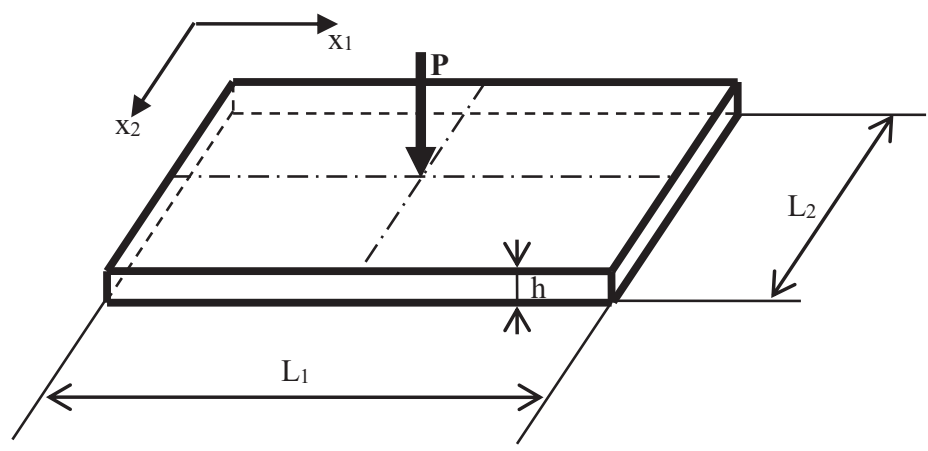

Figure 8. To the formulation of the boundary problem.

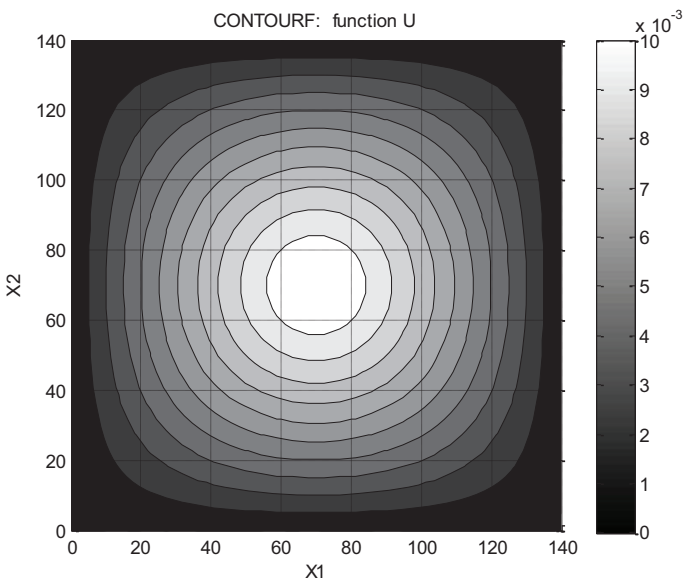

a)

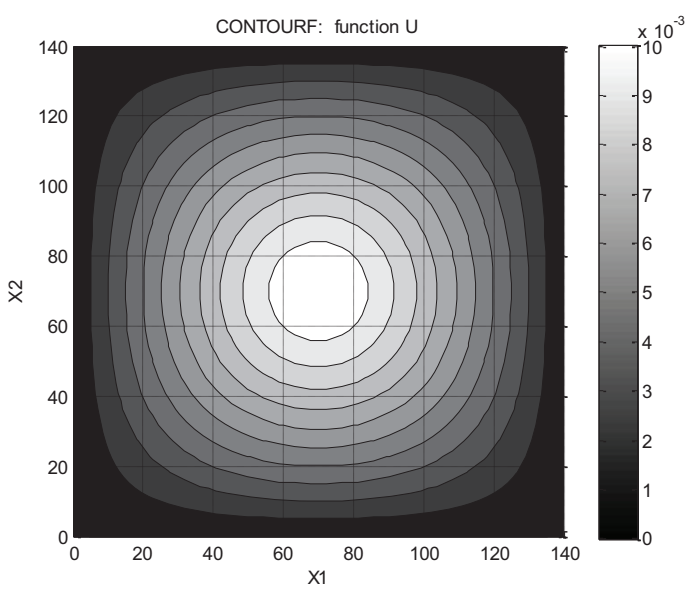

)

b) solution with the use of two-grid method.
It should be noted that the proposed method makes it possible to obtain a solution with the use of matrices of size $N_{1}^{2} \times N_{1}^{2}$ and vectors of size $N_{1}^{2}\left(N_{1}^{2}=(N / 2)^{2}\right)$.

\subsection{Numerical samples.}

Let us consider (as an example) the definition of bending a rectangular plate, hinged on the edges, loaded in the center by the concentrated force (Figure 8).

Design scheme of a rectangular plate is shown on Figure 8: $L_{1}=L_{2}=140 \mathrm{~mm}$ are dimensions of plate; $h=20 \mathrm{~cm}$ is thickness of plate; $E=3 \cdot 10^{3} \mathrm{kN} / \mathrm{cm}^{2}$ is modulus of elasticity of the material of plate; $v=0.16$ is Poisson's ratio of the material of plate; $P=100 \mathrm{kN}$ is parameter of concentrated load.

We can use finite difference method for numerical solution of the considering problem. Thus, we can get resultant system of equations with respect to the nodal deflections,

$$
A \bar{U}=\bar{f},
$$

where $A$ is matrix of coefficients; $\bar{f}$ is load vector; $\bar{U}$ is vector of unknown nodal deflections having the following structure

$$
\bar{U}=\left[\begin{array}{lllllll}
U_{1,1} & \ldots & U_{1, N} & \ldots & U_{N, 1} & \ldots & U_{N, N}
\end{array}\right]^{T}
$$

$U_{i, j}=u\left(x_{1, j}, x_{2, i}\right)$ is the deflection in the node $(i, j), i, j=1, \ldots, N$.

In accordance with the results of analysis graphs of deflections were obtained. Direct solution of the system (2.39) and solution defined by the formula (2.38) are presented at Figure 9. 
Let us consider (as an example) the static analysis of a trapezoidal beam-wall (Figure 10).

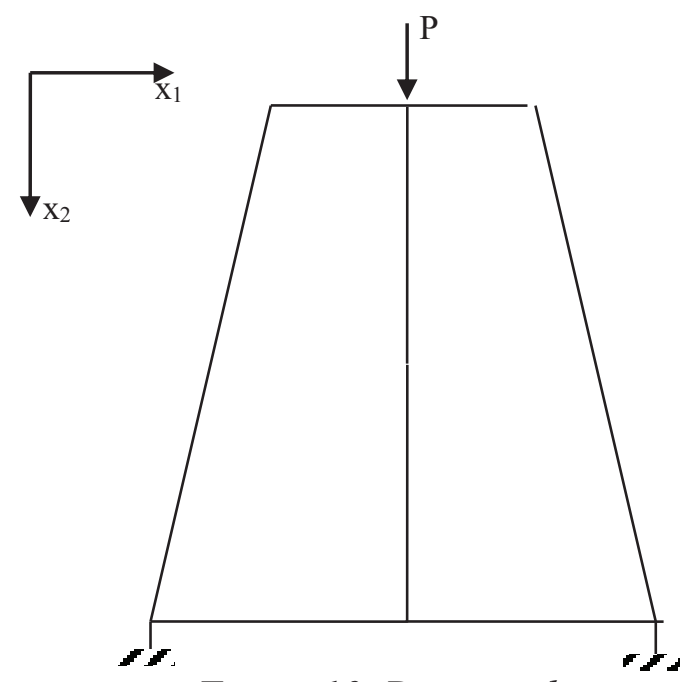

Figure 10. Design scheme.

Design scheme of a trapezoidal beams-wall is shown on Figure 10: height is equal to $140 \mathrm{~cm}$; width at base is equal to $140 \mathrm{~cm}$ and at the top of the structure is equal to $70 \mathrm{~cm} ; E=3 \cdot 10^{3}$ $\mathrm{kN} / \mathrm{cm}^{2}$ is the modulus of elasticity of the material of structure; $v=0.16$ is Poisson's ratio of elasticity of the material of structure; $P=100$ $\mathrm{kN}$ is parameter of concentrated load. Besides, we have fastening at the bottom corner points in both directions.

We can use finite element method for numerical solution of the considering problem. Thus, we can get resultant system of equations with respect to the nodal displacements $\left(u_{1}\right.$ and $\left.u_{2}\right)$,

$$
K \bar{U}=\bar{R},
$$

where $K$ is global stiffness matrix; $\bar{R}$ is global load vector; $\bar{U}$ is vector of unknown nodal displacements having the following structure,

$$
\begin{gathered}
\bar{U}=\left[\bar{u}_{1,1}^{T} \ldots u_{1, N}^{T} \ldots u_{N, 1}^{T} \ldots u_{N, N}^{T}\right]^{T} ; \\
\bar{u}_{i, j}=\left\lfloor\begin{array}{l}
u_{1}\left(x_{1, j}, x_{2, i}\right) \\
u_{2}\left(x_{1, j}, x_{2, i}\right)
\end{array}\right\rfloor
\end{gathered}
$$

are displacements $u_{1}$ and $u_{2}$ in the node $(i, j)$, $i, j=1, \ldots, N$.
Let us denote $P_{12}$ as the matrix operator of such a permutation, i.e.

$$
\bar{V}=P_{12} \bar{U} \quad \text { or } \quad \bar{U}=P_{12}^{T} \bar{V} .
$$

As a result, the resolving system (13) is converted to the form

$$
K_{v} \bar{V}=\bar{R}_{v}
$$

where we have

$$
K_{v}=P_{12} K P_{12}^{T} ; \quad \bar{R}_{v}=P_{12} \bar{R}
$$

Besides, we use the following block matrices in formulas (2.26)-(2.38):

$$
\begin{gathered}
\Phi_{1}^{b}=\left\lfloor\begin{array}{cc}
\Phi_{1} & 0 \\
0 & \Phi_{1}
\end{array}\right\rfloor ; \\
\Psi_{k, 1}^{b}=\left\lfloor\begin{array}{cc}
\Psi_{k, 1} & 0 \\
0 & \Psi_{k, 1}
\end{array}\right\rfloor, \quad k=1,2,3 .
\end{gathered}
$$

In accordance with the second equation of the formula (2.44), the solution of the initial problem (2.41) has the form:

$$
\bar{U}=P_{12}^{T}\left(\Phi_{1}^{b} \bar{w}_{1}+\sum_{k=1}^{3} \Psi_{k 1}^{b} \bar{w}_{k+1}\right)
$$

In accordance with the results of analysis graphs of displacements were obtained. Direct solution of the system (2.41) and solution defined by the formula (2.49) are presented at Figures 11-12.

\section{THREE-DIMENSIONAL PROBLEMS}

\subsection{General information.}

Let the initial three-dimensional domain be given as a rectangular prism [1]. Let $L_{1}, L_{2}$ and $L_{3}$ be lengths of sides of this prism in directions corresponding to Cartesian coordinates $x_{1}, x_{2}$ and $x_{3}$. 


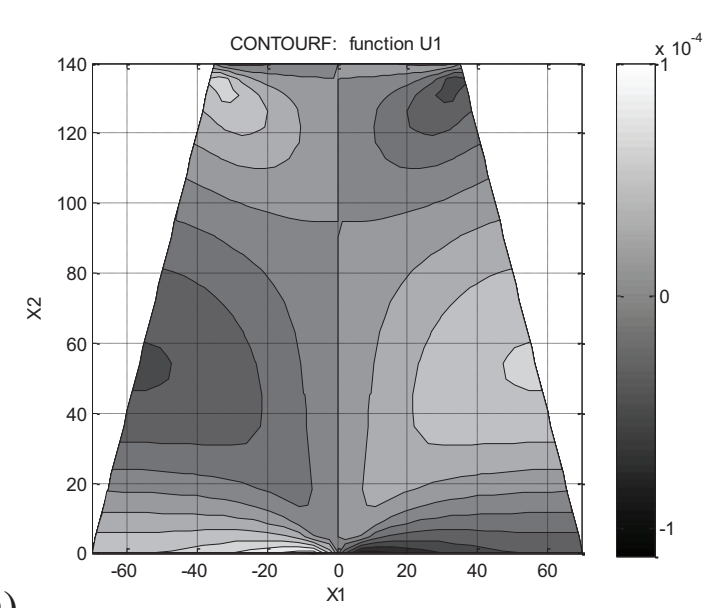

a)

b)

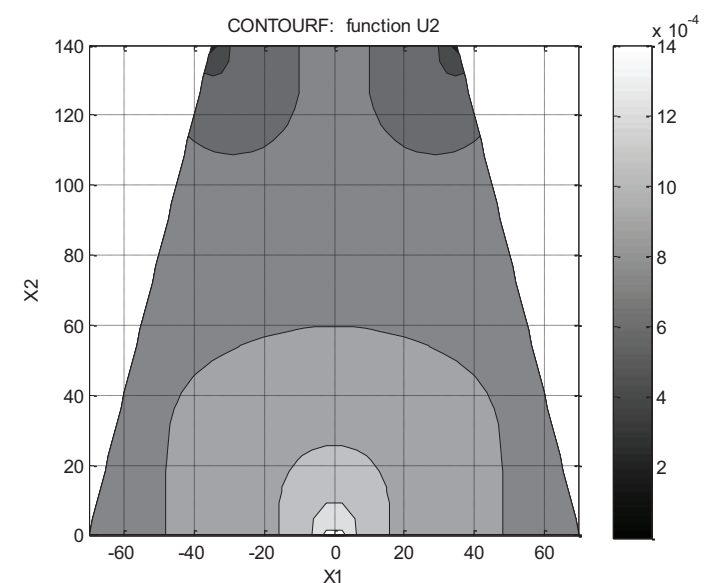

Figure 11. Solution of the boundary problem (displacements $u_{1}(a)$ and $u_{2}(b)$ ) in initial formulation.

a)

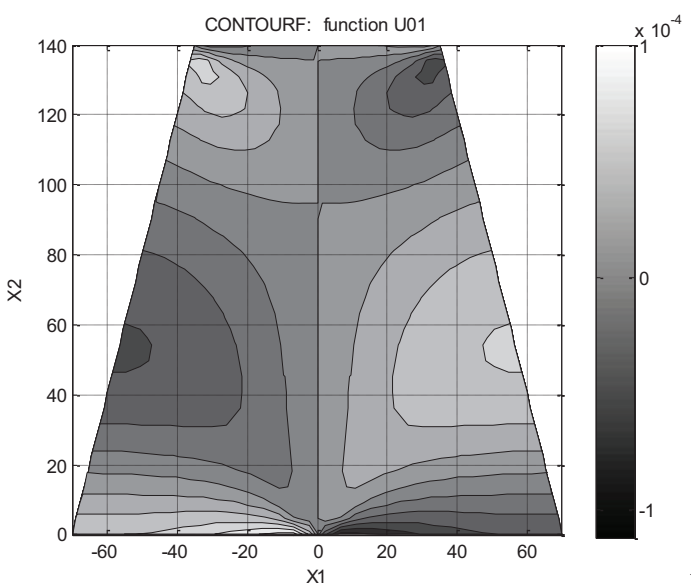

b)

Figure 12. Solution of the boundary problem (displacements $u_{1}(a)$ and $u_{2}(b)$ ) with the use of two-grid method.

We can use simple rectangular mesh (grid) for approximation of domain and divide each side of the rectangular prism (the initial domain) into $(N-1)$ equal parts. The corresponding mesh (grid) width are defined by formulas

$$
\begin{aligned}
h_{1}=L_{1} /(N-1) ; \quad h_{2}=L_{2} /(N-1) ; \\
h_{3}=L_{3} /(N-1) .
\end{aligned}
$$

Thus, the resulting mesh contains $N^{3}$ nodes. Let us introduce the mesh function

$\bar{u}=\left[\begin{array}{lllllll}u_{1,1,1} & \ldots & u_{1, N, 1} & \ldots & u_{N, N, 1} & \ldots & u_{N, N, N}\end{array}\right]^{T}$.
We can represent the mesh function (1.2) in the form

$$
\bar{u}=\sum_{j_{3}=1}^{N_{0}} \sum_{j_{2}=1}^{N_{0}} \sum_{j_{1}=1}^{N_{0}} u_{j_{2}, j_{1}, j_{3}}^{0} \bar{\Phi}_{j_{2}, j_{1}, j_{3}}^{0},
$$

where $\bar{\Phi}_{j_{2}, j_{1}, j_{3}}^{0}\left(i_{2}, i_{1}, i_{3}\right)$ is the $\left(j_{2}, j_{1}, j_{3}\right)$-th vector of a unit basis or a discrete zero-level Haar basis 
Marina L. Mozgaleva, Pavel A. Akimov, Taymuraz B. Kaytukov

$$
\begin{gathered}
\bar{\Phi}_{j_{2}, j_{1}, j_{3}}^{0}\left(i_{2}, i_{1}, i_{3}\right)= \\
=\left\{\begin{array}{l}
1,\left(i_{1}=j_{1}\right) \bigcap\left(i_{2}=j_{2}\right) \bigcap\left(i_{3}=j_{3}\right) \\
0,\left(i_{1} \neq j_{1}\right) \bigcup\left(i_{2} \neq j_{2}\right) \bigcup\left(i_{3} \neq j_{3}\right)
\end{array}\right. \\
1 \leq j_{2}, j_{1}, j_{3} \leq N_{0}=N ; \quad 1 \leq i_{2}, i_{1}, i_{3} \leq N_{0}=N \\
u_{j_{2}, j_{1}, j_{3}}^{0}=u_{j_{2}, j_{1}, j_{3}}, \quad 1 \leq j_{1}, j_{2}, j_{3} \leq N ; \\
N_{0}=N
\end{gathered}
$$

The mesh function (3.2) can also be represented in the form of an expansion in the Haar basis [17,9-25] of the first level:

$$
\begin{aligned}
\bar{u} & =\sum_{j_{3}=1}^{N_{1}} \sum_{j_{2}=1}^{N_{1}} \sum_{j_{1}=1}^{N_{1}} u_{j_{2}, j_{1}, j_{3}}^{1} \bar{\Phi}_{j_{2}, j_{1}, j_{3}}^{1}+ \\
& +\sum_{k=1}^{7} \sum_{j_{3}=1}^{N_{1}} \sum_{j_{2}=1}^{N_{1}} \sum_{j_{1}=1}^{N_{1}} v_{k, j_{2}, j_{1}, j_{3}}^{1} \bar{\Psi}_{k, j_{2}, j_{1}, j_{3}}^{1},
\end{aligned}
$$

where $\bar{\Phi}_{j_{2}, j_{1}, j_{3}}^{1}$ is $\left(j_{2}, j_{1}, j_{3}\right)$-th approximating vector of the discrete Haar basis of the first level,

$$
\begin{aligned}
\bar{\Phi}_{j_{2}, j_{1}, j_{3}}^{1} & =\alpha\left(\bar{\Phi}_{2 j_{2}-1,2 j_{1}-1,2 j_{3}-1}^{0}+\bar{\Phi}_{2 j_{2}-1,2 j_{1}, 2 j_{3}-1}^{0}+\right. \\
& +\bar{\Phi}_{2 j_{2}, 2 j_{1}-1,2 j_{3}-1}^{0}+\bar{\Phi}_{2 j_{2}, 2 j_{1}, 2 j_{3}-1}^{0}+ \\
& +\bar{\Phi}_{2 j_{2}-1,2 j_{1}-1,2 j_{3}}^{0}+\bar{\Phi}_{2 j_{2}-1,2 j_{1}, 2 j_{3}}^{0}+ \\
& \left.+\bar{\Phi}_{2 j_{2}, 2 j_{1}-1,2 j_{3}}^{0}+\bar{\Phi}_{2 j_{2}, 2 j_{1}, 2 j_{3}}^{0}\right)
\end{aligned}
$$

$\bar{\Psi}_{k, j_{2}, j_{1}, j_{3}}^{1}-\left(k, j_{2}, j_{1}, j_{3}\right)$-th refining vector of the discrete Haar basis of the first level,

$$
\begin{aligned}
\bar{\Psi}_{1, j_{2}, j_{1}, j_{3}}^{1} & =\alpha\left(\bar{\Phi}_{2 j_{2}-1,2 j_{1}-1,2 j_{3}-1}^{0}-\bar{\Phi}_{2 j_{2}-1,2 j_{1}, 2 j_{3}-1}^{0}+\right. \\
& +\bar{\Phi}_{2 j_{2}, 2 j_{1}-1,2 j_{3}-1}^{0}-\bar{\Phi}_{2 j_{2}, 2 j_{1}, 2 j_{3}-1}^{0}+ \\
& +\bar{\Phi}_{2 j_{2}-1,2 j_{1}-1,2 j_{3}}^{0}-\bar{\Phi}_{2 j_{2}-1,2 j_{1}, 2 j_{3}}^{0}+ \\
& \left.+\bar{\Phi}_{2 j_{2}, 2 j_{1}-1,2 j_{3}}^{0}-\bar{\Phi}_{2 j_{2}, 2 j_{1}, 2 j_{3}}^{0}\right) ; \\
\bar{\Psi}_{2, j_{2}, j_{1}, j_{3}}^{1} & =\alpha\left(\bar{\Phi}_{2 j_{2}-1,2 j_{1}-1,2 j_{3}-1}^{0}+\bar{\Phi}_{2 j_{2}-1,2 j_{1}, 2 j_{3}-1}^{0}-\right. \\
& -\bar{\Phi}_{2 j_{2}, 2 j_{1}-1,2 j_{3}-1}^{0}-\bar{\Phi}_{2 j_{2}, 2 j_{1}, 2 j_{3}-1}^{0}+ \\
& +\bar{\Phi}_{2 j_{2}-1,2 j_{1}-1,2 j_{3}}^{0}+\bar{\Phi}_{2 j_{2}-1,2 j_{1}, 2 j_{3}}^{0}- \\
& \left.-\bar{\Phi}_{2 j_{2}, 2 j_{1}-1,2 j_{3}}^{0}-\bar{\Phi}_{2 j_{2}, 2 j_{1}, 2 j_{3}}^{0}\right) ;
\end{aligned}
$$

$$
\begin{aligned}
\bar{\Psi}_{3, j_{2}, j_{1}, j_{3}}^{1} & =\alpha\left(\bar{\Phi}_{2 j_{2}-1,2 j_{1}-1,2 j_{3}-1}^{0}-\bar{\Phi}_{2 j_{2}-1,2 j_{1}, 2 j_{3}-1}^{0}-\right. \\
& -\bar{\Phi}_{2 j_{2}, 2 j_{1}-1,2 j_{3}-1}^{0}+\bar{\Phi}_{2 j_{2}, 2 j_{1}, 2 j_{3}-1}^{0}+ \\
& +\bar{\Phi}_{2 j_{2}-1,2 j_{1}-1,2 j_{3}}^{0}-\bar{\Phi}_{2 j_{2}-1,2 j_{1}, 2 j_{3}}^{0}- \\
& \left.-\bar{\Phi}_{2 j_{2}, 2 j_{1}-1,2 j_{3}}^{0}+\bar{\Phi}_{2 j_{2}, 2 j_{1}, 2 j_{3}}^{0}\right)
\end{aligned}
$$

$$
\begin{aligned}
\bar{\Psi}_{4, j_{2}, j_{1}, j_{3}}^{1} & =\alpha\left(\bar{\Phi}_{2 j_{2}-1,2 j_{1}-1,2 j_{3}-1}^{0}+\bar{\Phi}_{2 j_{2}-1,2 j_{1}, 2 j_{3}-1}^{0}+\right. \\
& +\bar{\Phi}_{2 j_{2}, 2 j_{1}-1,2 j_{3}-1}^{0}+\bar{\Phi}_{2 j_{2}, 2 j_{1}, 2 j_{3}-1}^{0}- \\
& -\bar{\Phi}_{2 j_{2}-1,2 j_{1}-1,2 j_{3}}^{0}-\bar{\Phi}_{2 j_{2}-1,2 j_{1}, 2 j_{3}}^{0}- \\
& \left.-\bar{\Phi}_{2 j_{2}, 2 j_{1}-1,2 j_{3}}^{0}-\bar{\Phi}_{2 j_{2}, 2 j_{1}, 2 j_{3}}^{0}\right) ;
\end{aligned}
$$

$$
\begin{aligned}
\bar{\Psi}_{5, j_{2}, j_{1}, j_{3}}^{1} & =\alpha\left(\bar{\Phi}_{2 j_{2}-1,2 j_{1}-1,2 j_{3}-1}^{0}-\bar{\Phi}_{2 j_{2}-1,2 j_{1}, 2 j_{3}-1}^{0}+\right. \\
& +\bar{\Phi}_{2 j_{2}, 2 j_{1}-1,2 j_{3}-1}^{0}-\bar{\Phi}_{2 j_{2}, 2 j_{1}, 2 j_{3}-1}^{0}- \\
& -\bar{\Phi}_{2 j_{2}-1,2 j_{1}-1,2 j_{3}}^{0}+\bar{\Phi}_{2 j_{2}-1,2 j_{1}, 2 j_{3}}^{0}- \\
& \left.-\bar{\Phi}_{2 j_{2}, 2 j_{1}-1,2 j_{3}}^{0}+\bar{\Phi}_{2 j_{2}, 2 j_{1}, 2 j_{3}}^{0}\right) ;
\end{aligned}
$$

$$
\begin{aligned}
\bar{\Psi}_{6, j_{2}, j_{1}, j_{3}}^{1} & =\alpha\left(\bar{\Phi}_{2 j_{2}-1,2 j_{1}-1,2 j_{3}-1}^{0}+\bar{\Phi}_{2 j_{2}-1,2 j_{1}, 2 j_{3}-1}^{0}-\right. \\
& -\bar{\Phi}_{2 j_{2}, 2 j_{1}-1,2 j_{3}-1}^{0}-\bar{\Phi}_{2 j_{2}, 2 j_{1}, 2 j_{3}-1}^{0}- \\
& -\bar{\Phi}_{2 j_{2}-1,2 j_{1}-1,2 j_{3}}^{0}-\bar{\Phi}_{2 j_{2}-1,2 j_{1}, 2 j_{3}}^{0}+ \\
& \left.+\bar{\Phi}_{2 j_{2}, 2 j_{1}-1,2 j_{3}}^{0}+\bar{\Phi}_{2 j_{2}, 2 j_{1}, 2 j_{3}}^{0}\right) ;
\end{aligned}
$$$$
\bar{\Psi}_{7, j_{2}, j_{1}, j_{3}}^{1}=\alpha\left(\bar{\Phi}_{2 j_{2}-1,2 j_{1}-1,2 j_{3}-1}^{0}-\bar{\Phi}_{2 j_{2}-1,2 j_{1}, 2 j_{3}-1}^{0}\right.
$$$$
-\bar{\Phi}_{2 j_{2}, 2 j_{1}-1,2 j_{3}-1}^{0}+\bar{\Phi}_{2 j_{2}, 2 j_{1}, 2 j_{3}-1}^{0}-
$$$$
-\bar{\Phi}_{2 j_{2}-1,2 j_{1}-1,2 j_{3}}^{0}+\bar{\Phi}_{2 j_{2}-1,2 j_{1}, 2 j_{3}}^{0}+
$$$$
\left.+\bar{\Phi}_{2 j_{2}, 2 j_{1}-1,2 j_{3}}^{0}-\bar{\Phi}_{2 j_{2}, 2 j_{1}, 2 j_{3}}^{0}\right) \text {; }
$$

$$
\begin{gathered}
u_{j_{2}, j_{1}, j_{3}}^{1}=\left(\bar{u}, \bar{\Phi}_{j_{2}, j_{1}, j_{3}}^{1}\right) ; \\
v_{k, j_{2}, j_{1}, j_{3}}^{1}=\left(\bar{u}, \bar{\Psi}_{k, j_{2}, j_{1}, j_{3}}^{1}\right), k=1, \ldots, 7 ; \\
\alpha=1 /(2 \sqrt{2}) ; \quad N_{1}=N / 2
\end{gathered}
$$

$\alpha$ is normalizing factor.

In accordance with (3.7), the mesh function $\bar{u}$ is represented as a sum in which the first summand (the first sum) is its approximation on the grid of the first level including $N_{1}^{3}$ nodes, and the second term (the second sum) is called the refinement (the complement to the initial state) on the grid the first level. The representation (3.6) can be written in the form 


$$
\begin{aligned}
& \bar{u}=\bar{u}_{1}^{0}+\sum_{k=1}^{7} \bar{v}_{k, 1}^{0}, \\
& \bar{u}_{1}^{0}=\sum_{j_{3}=1}^{N_{1}} \sum_{j_{2}=1}^{N_{1}} \sum_{j_{1}=1}^{N_{1}} u_{j_{2}, j_{1}, j_{3}}^{1} \bar{\Phi}_{j_{2}, j_{1}, j_{3}}^{1}= \\
& =\Phi_{1}\left(\Phi_{1}, \bar{u}\right)=\Phi_{1} \Phi_{1}^{T} \bar{u} ; \\
& \bar{v}_{k, 1}^{0}=\sum_{j_{3}=1}^{N_{1}} \sum_{j_{2}=1}^{N_{1}} \sum_{j_{1}=1}^{N_{1}} v_{k, j_{2}, j_{1}, j_{3}}^{1} \bar{\Psi}_{k, j_{2}, j_{1}, j_{3}}^{1}= \\
& =\Psi_{k, 1}\left(\Psi_{k, 1}, \bar{u}\right)=\Psi_{k, 1} \Psi_{k, 1}^{T} \bar{u}, k=1, \ldots, 7 ; \\
& \Phi_{1}=
\end{aligned}
$$

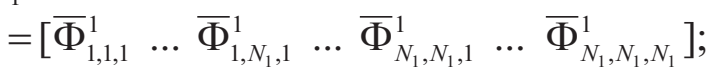

$$
\begin{aligned}
& \Psi_{k, 1}= \\
& =\left[\begin{array}{llllll}
\bar{\Psi}_{k, 1,1,1}^{1} & \ldots & \bar{\Psi}_{k, 1, N_{1}, 1}^{1} & \ldots & \bar{\Psi}_{k, N_{1}, N_{1}, 1}^{1} & \ldots \\
\Psi_{k, N_{1}, N_{1}, N_{1}}^{1}
\end{array}\right], \\
& k=1, \ldots, 7 \text {. }
\end{aligned}
$$

Due to the orthonormality of the Haar basis $[2,3,5,6]$, the operators

$$
P_{\Phi}=\Phi_{1} \Phi_{1}^{T}, \quad P_{\Psi, k}=\Psi_{k, 1} \Psi_{k, 1}^{T}, \quad k=1, \ldots, 7
$$

are projectors of the space of vector functions of the original grid to the space of their approximation on the first-level grid and its complement (the refining component) to the initial state, respectively.

3.2. Basic scheme of the two-grid method. Let systems of linear algebraic equations

$$
A \bar{u}=\bar{f}
$$

are discrete analogs of some operator equation defined on a given rectangular prism of order $N^{3}$.

We can substitute in (3.22) the expression for $\bar{u}$ in the form (3.16). Then we can multiply, in turn, both sides of the equality on the left by the matrices $\Phi_{1}^{T}$ and $\Psi_{k, 1}^{T}, k=1,2,3,4,5,6,7$. Thus we have

$$
\begin{gathered}
\Phi_{1}^{T} A \bar{u}_{1}^{0}+\sum_{k=1}^{7} \Phi_{1}^{T} A \Psi_{k, 1} \vec{v}_{k}^{1}=\Phi_{1}^{T} \bar{f}, \\
\Psi_{k, 1}^{T} A \bar{u}_{1}^{0}+\sum_{k=1}^{7} \Psi_{k, 1}^{T} A \Psi_{k, 1} \bar{v}_{k}^{1}=\Psi_{k, 1}^{T} \bar{f}, \quad k=1, \ldots, 7 .
\end{gathered}
$$

Equations (3.25) and (3.26) can be combined in the system

$$
\sum_{i=1}^{4} A_{i, j} \bar{w}_{j}=\bar{f}_{i}, \quad i=1, \ldots, 8
$$

where $A_{i, j}$ are block matrices of size $N_{1}^{3} \times N_{1}^{3}$; $\bar{f}_{i}$ and $\bar{w}_{j}$ are block vectors of size $N_{1}^{3}$,

$$
\begin{gathered}
A_{1,1}=\Phi_{1}^{T} A \Phi_{1} ; \quad A_{1, k+1}=\Phi_{1}^{T} A \Psi_{k, 1}, \\
A_{k+1,1}=\Psi_{k, 1}^{T} A \Phi_{1}, \quad k=1, \ldots, 7 ; \\
A_{k+1, p+1}=\Psi_{k, 1}^{T} A \Psi_{p+1}, \quad k, p=1,2,3,4,5,6,7 ; \\
\bar{f}_{1}=\Phi_{1}^{T} \bar{f}, \quad \bar{f}_{k+1}=\Psi_{k, 1}^{T} \bar{f}, \quad k=1, \ldots, 7 ; \\
\bar{w}_{1}=\bar{u}^{1}, \quad \bar{w}_{k+1}=v_{k}^{1}, \quad k=1, \ldots, 7 .
\end{gathered}
$$

We can find the solution of the system (3.27) using the block Gaussian method.

The expanded block matrix has the form:

$\left[\begin{array}{cccccccc|c}A_{1,1} & A_{1,2} & A_{1,3} & A_{1,4} & A_{1,5} & A_{1,6} & A_{1,7} & A_{1,8} & \bar{f}_{1} \\ A_{2,1} & A_{2,2} & A_{2,3} & A_{2,4} & A_{2,5} & A_{2,6} & A_{2,7} & A_{2,8} & \bar{f}_{2} \\ A_{3,1} & A_{3,2} & A_{3,3} & A_{3,4} & A_{3,5} & A_{3,6} & A_{3,7} & A_{3,8} & \bar{f}_{3} \\ A_{4,1} & A_{4,2} & A_{4,3} & A_{4,4} & A_{4,5} & A_{4,6} & A_{4,7} & A_{4,8} & \bar{f}_{4} \\ A_{5,1} & A_{5,2} & A_{5,3} & A_{5,4} & A_{5,5} & A_{5,6} & A_{5,7} & A_{5,8} & \bar{f}_{5} \\ A_{6,1} & A_{6,2} & A_{6,3} & A_{6,4} & A_{6,5} & A_{6,6} & A_{6,7} & A_{6,8} & \bar{f}_{6} \\ A_{7,1} & A_{7,2} & A_{7,3} & A_{7,4} & A_{7,5} & A_{7,6} & A_{7,7} & A_{7,8} & \bar{f}_{7} \\ A_{8,1} & A_{8,2} & A_{8,3} & A_{8,4} & A_{8,5} & A_{8,6} & A_{8,7} & A_{8,8} & \bar{f}_{8}\end{array}\right]$.

We have the following result of forward algorithm: 


$$
\left[\begin{array}{cccccccc|c}
A_{1,1}^{0} & A_{1,2}^{0} & A_{1,3}^{0} & A_{1,4}^{0} & A_{1,5}^{0} & A_{1,6}^{0} & A_{1,7}^{0} & A_{1,8}^{0} & \bar{f}_{1}^{0} \\
0 & A_{2,2}^{1} & A_{2,3}^{1} & A_{2,4}^{1} & A_{2,5}^{1} & A_{2,6}^{1} & A_{2,7}^{1} & A_{2,8}^{1} & \bar{f}_{2}^{1} \\
0 & 0 & A_{3,3}^{2} & A_{3,4}^{2} & A_{3,5}^{2} & A_{3,6}^{2} & A_{3,7}^{2} & A_{3,8}^{2} & \bar{f}_{3}^{2} \\
0 & 0 & 0 & A_{4,4}^{3} & A_{4,5}^{3} & A_{4,6}^{3} & A_{4,7}^{3} & A_{4,8}^{3} & \bar{f}_{4}^{3} \\
0 & 0 & 0 & 0 & A_{5,5}^{4} & A_{5,6}^{4} & A_{5,7}^{4} & A_{5,8}^{4} & \bar{f}_{5}^{4} \\
0 & 0 & 0 & 0 & 0 & A_{6,6}^{5} & A_{6,7}^{5} & A_{6,8}^{5} & \bar{f}_{6}^{5} \\
0 & 0 & 0 & 0 & 0 & 0 & A_{7,7}^{6} & A_{7,8}^{6} & \bar{f}_{7}^{6} \\
0 & 0 & 0 & 0 & 0 & 0 & 0 & A_{8,8}^{7} & \bar{f}_{8}^{7}
\end{array}\right],
$$

where

$$
\begin{array}{r}
A_{i, j}^{k}=A_{i, j}^{k-1}-C_{i, k} A_{k, j}^{k-1}, \quad k=1, \ldots, 7, \\
i=k+1, \ldots, 8, \quad j=k+1, \ldots, 8 ; \\
\bar{f}_{i}^{k}=\bar{f}_{i}^{k-1}-C_{i, k} \bar{f}_{k}^{k-1}, \quad k=1, \ldots, 7, \\
i=k+1, \ldots, 8 ; \\
C_{i, k}=A_{i, k}^{k-1}\left(A_{k, k}^{k-1}\right)^{-1}, \quad k=1, \ldots, 7, \\
i=k+1, \ldots, 8 .
\end{array}
$$

We have the following result of backward algorithm

$$
\begin{gathered}
\bar{w}_{8}=\left(A_{8,8}^{7}\right)^{-1} \bar{f}_{8}^{7} \\
\bar{w}_{i}=\left(A_{i, i}^{i-1}\right)^{-1}\left(\bar{f}_{i}^{i-1}-\sum_{j=i+1}^{4} A_{i, i}^{i-1} \bar{w}_{j}\right), \quad i=7, \ldots, 1 .
\end{gathered}
$$

In accordance with formulas (3.18)-(3.20) solution of the considering problem (3.24) has the form

$$
\begin{aligned}
\bar{u} & =\bar{u}_{1}^{0}+\sum_{k=1}^{7} \bar{v}_{k, 1}^{0}= \\
& =\Phi_{1} \bar{u}^{1}+\sum_{k=1}^{7} \Psi_{k, 1} \bar{v}_{k}^{1}=\Phi_{1} \bar{w}_{1}+\sum_{k=1}^{7} \Psi_{k, 1} \bar{w}_{k+1}
\end{aligned}
$$

It should be noted that the proposed method makes it possible to obtain a solution with the use of matrices of size $N_{1}^{3} \times N_{1}^{3}$ and vectors of size $N_{1}^{3}$.

\section{REFERENCES}

1. Mozgaleva M.L., Akimov P.A. Dvuhsetochnyj Metod Rascheta Stroitel'nyh Konstrukcij na Osnove Ispol'zovaniya Diskretnogo Bazisa Haara. CHast' 1: Odnomernye Problemy [Two-Grid method of Structural Analysis Based on Discrete Haar Basis. Part 1: One-Dimensional Problems]. // International Journal for Computational Civil and Structural Engineering, Volume 13, Issue 4, 2017, pp. 128-139.

2. Mozgaleva M.L., Akimov P.A. K Voprosu ob Otscenke Vliyaniya Spryamleniya Approksimiruyushchej Setki na Chislennoe Reshenie Kraevoj Zadachi [About the Problem of the Assessment of the Impact of the Flatness of the Approximating Mesh on the Numerical Solution of the Boundary Problem]. // International Journal for Computational Civil and Structural Engineering, Volume 11, Issue 1, 2015, pp. 115-120.

3. Mozgaleva M.L., Akimov P.A. Ob Issledovanii Diskretnyh Metodov Polucheniya Lokal'nyh Reshenij Odnomernyh Zadach Rascheta Konstrukcij [About the Study of Discrete Methods for Obtaining Local Solutions to One-Dimensional Problems of Structural Analysis]. // International Journal for Computational Civil and Structural Engineering, Volume 11, Issue 1, 2015, pp. 121-134.

4. Mozgaleva M.L., Akimov P.A., Semin D.F. Lokal'noe Chislennoe Reshenie Kraevyh Zadach Stroitel'noj Mekhaniki s Ispol'zovaniem Gibridnogo Diskretnogo Vejvet-Bazisa [Local Numerical Solution of Boundary Problems of Structural Mechanics With the Use of Hybrid Discrete Wavelet Basis]. // International Journal for Computational Civil and Structural Engineering, Volume 14, Issue 1, 2018, pp. 113125.

5. Akimov P.A., Mojtaba Aslami. Theoretical Foundations of Correct Wavelet-Based Approach to Local Static Analysis of Bernoulli Beam. // Applied Mechanics and Ma- 
terials, 2014, Vols. 580-583, pp. 29242927.

6. Akimov P.A., Mozgaleva M.L. Correct Wavelet-based Multilevel DiscreteContinual Methods for Local Solution of Boundary Problems of Structural Analysis. // Applied Mechanics and Materials, 2013, Vols. 353-356, pp. 3224-3227.

7. Akimov P.A., Mozgaleva M.L. Correct Wavelet-based Multilevel Numerical Method of Local Solution of Boundary Problems of Structural Analysis. // Applied Mechanics and Materials, 2012, Vols. 166-169, pp. 3155-3158.

8. Akimov P.A., Mozgaleva M.L. Method of Extended Domain and General Principles of Mesh Approximation for Boundary Problems of Structural Analysis. // Applied Mechanics and Materials, 2014, Vols. 580-583, pp. 2898-2902.

9. Arbabi S., Nazari A., Darvishi M.T. A Two-Dimensional Haar Wavelets Method for Solving Systems of PDEs. // Applied Mathematics and Computation, 2017, Volume 292, pp. 33-46.

10. Aziz I., Amin R. Numerical Solution of a Class of Delay Differential and Delay Partial Differential Equations via Haar Wavelet. // Applied Mathematical Modelling, 2016, Volume 40, Issues 23-24, pp. 1028610299.

11. Aziz I., Siraj-ul-Islam, Asif M. Haar Wavelet Collocation Method for ThreeDimensional Elliptic Partial Differential Equations. // Computers \& Mathematics with Applications, 2017, Volume 73, Issue 9, pp. 2023-2034.

12. Babaaghaie A., Maleknejad K. Numerical Solution of Integro-Differential Equations of High Order by Wavelet Basis, its Algorithm and Convergence Analysis. // Journal of Computational and Applied Mathematics, 2017, Volume 325, pp. 125-133.

13. Babaaghaie A., Maleknejad K. Numerical Solutions of Nonlinear Two-Dimensional Partial Volterra Integro-Differential Equations by Haar Wavelet. // Journal of Com- putational and Applied Mathematics, 2017, Volume 317, pp. 643-651.

14. Dai Q., Cao Q., Chen Y. Frequency Analysis of Rotating Truncated Conical Shells Using the Haar Wavelet Method. // Applied Mathematical Modelling, 2018, Volume 57, pp. 603-613.

15. Ezzati R., Sadatrasoul S.M. On Numerical Solution of Two-Dimensional Nonlinear Urysohn Fuzzy Integral Equations Based on Fuzzy Haar Wavelets. // Fuzzy Sets and Systems, 2017, Volume 309, pp. 145-164.

16. Hsiao C.-H. A Haar Wavelets Method of Solving Differential Equations Characterizing the Dynamics of a Current Collection System for an Electric Locomotive. // Applied Mathematics and Computation, 2015, Volume 265, pp. 928-935.

17. Kaur H., Mittal R.C., Mishra V. Haar Wavelet Solutions of Nonlinear Oscillator Equations. // Applied Mathematical Modelling, 2014, Volume 38, Issues 21-22, pp. 4958-4971.

18. Mojtaba Aslami, Akimov P.A. Waveletbased finite element method for multilevel local plate analysis. // Thin-Walled Structures, Volume 98, Part B (2015-2016), pp. 392-402.

19. Mozgaleva M.L., Akimov P.A. Multilevel wavelet-based numerical method of local structural analysis for three-dimensional problem. // Procedia Engineering, 2015, Vol. 111, pp. 569-574.

20. Prakash B., Setia A., Alapatt D. Numerical Solution of Nonlinear Fractional SEIR Epidemic Model by Using Haar Wavelets. // Journal of Computational Science, 2017, Volume 22, pp. 109-118.

21. Shiralashetti S.C., Deshi A.B., Mutalik Desai P.B. Haar Wavelet Collocation Method for the Numerical Solution of Singular Initial Value Problems. // Ain Shams Engineering Journal, 2016, Volume 7, Issue 2, pp. 663-670.

22. Shiralashetti S.C., Kantli M.H., Deshi A.B. A New Wavelet Multigrid Method for the Numerical Solution of Elliptic Type 
Differential Equations. // Alexandria Engineering Journal, 2018, Volume 57, Issue 1, pp. 203-209.

23. Wang L., Ma Y., Meng Z. Haar Wavelet Method for Solving Fractional Partial Differential Equations Numerically. // Applied Mathematics and Computation, 2014, Volume 227, pp. 66-76.

24. Xie X., Jin G., Yan Y., Shi S.X., Liu Z. Free Vibration Analysis of Composite Laminated Cylindrical Shells Using the Haar Wavelet Method. // Composite Structures, 2014, Volume 109, pp. 169-177.

\section{СПИСОК ЛИТЕРАТУРЫ}

1. Мозгалева М.Л., Акимов П.А. Двухсеточный метод расчета строительных конструкций на основе использования дискретного базиса Хаара. Часть 1: Одномерные проблемы. // International Journal for Computational Civil and Structural Engineering / Международный журнал по расчету гражданских и строительных конструкций, Volume 13, Issue 4, 2017, pp. 128-139.

2. Мозгалева М.Л., Акимов П.А. К вопросу об оценке влияния спрямления аппроксимирующей сетки на численное решение краевой задачи. // International Journal for Computational Civil and Structural Engineering / Международный журнал по расчету гражданских и строительных конструкций, Volume 11, Issue 1, 2015, pp. 115-120.

3. Мозгалева М.Л., Акимов П.А. Об исследовании дискретных методов получения локальных решений одномерных задач расчета конструкций. // International Journal for Computational Civil and Structural Engineering / Международный журнал по расчету гражданских и строительных конструкций, Volume 11, Issue 1, 2015, pp. 121-134.

4. Мозгалева М.Л., Акимов П.А., Семин Д.Ф. Локальное численное решение кра- евых задач строительной механики с использованием гибридного дискретного вейвет-базиса. // International Journal for Computational Civil and Structural Engineering / Международный журнал по расчету гражданских и строительных конструкций, Volume 14, Issue 1, 2018, pp. 113-125.

5. Akimov P.A., Mojtaba Aslami. Theoretical Foundations of Correct Wavelet-Based Approach to Local Static Analysis of Bernoulli Beam. // Applied Mechanics and Materials, 2014, Vols. 580-583, pp. 29242927.

6. Akimov P.A., Mozgaleva M.L. Correct Wavelet-based Multilevel DiscreteContinual Methods for Local Solution of Boundary Problems of Structural Analysis. // Applied Mechanics and Materials, 2013, Vols. 353-356, pp. 3224-3227.

7. Akimov P.A., Mozgaleva M.L. Correct Wavelet-based Multilevel Numerical Method of Local Solution of Boundary Problems of Structural Analysis. // Applied Mechanics and Materials, 2012, Vols. 166-169, pp. 3155-3158.

8. Akimov P.A., Mozgaleva M.L. Method of Extended Domain and General Principles of Mesh Approximation for Boundary Problems of Structural Analysis. // Applied Mechanics and Materials, 2014, Vols. 580-583, pp. 2898-2902.

9. Arbabi S., Nazari A., Darvishi M.T. A Two-Dimensional Haar Wavelets Method for Solving Systems of PDEs. // Applied Mathematics and Computation, 2017, Volume 292, pp. 33-46.

10. Aziz I., Amin R. Numerical Solution of a Class of Delay Differential and Delay Partial Differential Equations via Haar Wavelet. // Applied Mathematical Modelling, 2016, Volume 40, Issues 23-24, pp. 1028610299.

11. Aziz I., Siraj-ul-Islam, Asif M. Haar Wavelet Collocation Method for ThreeDimensional Elliptic Partial Differential Equations. // Computers \& Mathematics 
with Applications, 2017, Volume 73, Issue 9, pp. 2023-2034.

12. Babaaghaie A., Maleknejad K. Numerical Solution of Integro-Differential Equations of High Order by Wavelet Basis, its Algorithm and Convergence Analysis. // Journal of Computational and Applied Mathematics, 2017, Volume 325, pp. 125-133.

13. Babaaghaie A., Maleknejad K. Numerical Solutions of Nonlinear Two-Dimensional Partial Volterra Integro-Differential Equations by Haar Wavelet. // Journal of Computational and Applied Mathematics, 2017, Volume 317, pp. 643-651.

14. Dai Q., Cao Q., Chen Y. Frequency Analysis of Rotating Truncated Conical Shells Using the Haar Wavelet Method. // Applied Mathematical Modelling, 2018, Volume 57, pp. 603-613.

15. Ezzati R., Sadatrasoul S.M. On Numerical Solution of Two-Dimensional Nonlinear Urysohn Fuzzy Integral Equations Based on Fuzzy Haar Wavelets. // Fuzzy Sets and Systems, 2017, Volume 309, pp. 145-164.

16. Hsiao C.-H. A Haar Wavelets Method of Solving Differential Equations Characterizing the Dynamics of a Current Collection System for an Electric Locomotive. // Applied Mathematics and Computation, 2015, Volume 265, pp. 928-935.

17. Kaur H., Mittal R.C., Mishra V. Haar Wavelet Solutions of Nonlinear Oscillator Equations. // Applied Mathematical Modelling, 2014, Volume 38, Issues 21-22, pp. 4958-4971.

18. Mojtaba Aslami, Akimov P.A. Waveletbased finite element method for multilevel local plate analysis. // Thin-Walled Structures, Volume 98, Part B (2015-2016), pp. 392-402.

19. Mozgaleva M.L., Akimov P.A. Multilevel wavelet-based numerical method of local structural analysis for three-dimensional problem. // Procedia Engineering, 2015, Vol. 111, pp. 569-574.

20. Prakash B., Setia A., Alapatt D. Numerical Solution of Nonlinear Fractional SEIR
Epidemic Model by Using Haar Wavelets. // Journal of Computational Science, 2017, Volume 22, pp. 109-118.

21. Shiralashetti S.C., Deshi A.B., Mutalik Desai P.B. Haar Wavelet Collocation Method for the Numerical Solution of Singular Initial Value Problems. // Ain Shams Engineering Journal, 2016, Volume 7, Issue 2, pp. 663-670.

22. Shiralashetti S.C., Kantli M.H., Deshi A.B. A New Wavelet Multigrid Method for the Numerical Solution of Elliptic Type Differential Equations. // Alexandria Engineering Journal, 2018, Volume 57, Issue 1, pp. 203-209.

23. Wang L., Ma Y., Meng Z. Haar Wavelet Method for Solving Fractional Partial Differential Equations Numerically. // Applied Mathematics and Computation, 2014, Volume 227, pp. 66-76.

24. Xie X., Jin G., Yan Y., Shi S.X., Liu Z. Free Vibration Analysis of Composite Laminated Cylindrical Shells Using the Haar Wavelet Method. // Composite Structures, 2014, Volume 109, pp. 169-177.

Marina L. Mozgaleva, PhD, Professor, Department of Applied Mathematics, National Research Moscow State University of Civil Engineering, 26, Yaroslavskoe Shosse, Moscow, 129337, Russia;

phone/fax: +7(499) 183-59-94;

E-mail: marina.mozgaleva@gmail.com.

Pavel A. Akimov, Full Member of the Russian Academy of Architecture and Construction Sciences, PhD, Professor; Executive Scientific Secretary of Russian Academy of Architecture and Construction Sciences; Vice-Director for Science Activities, Scientific Research Center "StaDyO"; Professor of Department of Architecture and Construction, Peoples' Friendship University of Russia; Professor of Department of Structural Mechanics, Tomsk State University of Architecture and Building; 24, Ul. Bolshaya Dmitrovka, 107031, Moscow, Russia; phone +7(495) 625-71-63; fax: +7 (495) 650-27-31; E-mail: akimov@raasn.ru,pavel.akimov@gmail.com.

Taymuraz B. Kaytukov, Advisor of the Russian Academy of Architecture and Construction Sciences, Associated Professor, Ph.D.; Deputy Executive Scientific Secretary of Russian Academy of Architecture and Construction Sciences; Central Institute for Research and Design of the 
Ministry of Construction and Housing and Communal Services of the Russian Federation; 24, U1. Bolshaya Dmitrovka, 107031, Moscow, Russia; phone +7(495) 625-81-53; fax: +7 (495) 650-27-31; Email: kaytukov@raasn.ru, tkaytukov@gmail.com.

Мозгалева Марина Леонидовна, доцент, доктор технических наук, профессор кафедры прикладной математики, Национальный исследовательский Московский государственный строительный университет (НИУ МГСУ), Россия, 129337, Москва, Ярославское шоссе, д.26, тел./факс: +7(499) 183-59-94, E-mail: marina.mozgaleva@gmail.com.

Акимов Павел Алексеевич, академик РААСН, профессор, доктор технических наук; главный ученый секретарь Российской академии архитектуры и строительных наук; заместитель генерального директора по науке $3 \mathrm{AO}$ «Научно-исследовательский центр СтаДиО»; профессор Департамента архитектуры и строительства Российского университета дружбы народов; профессор кафедры строительной механики Томского государственного архитектурно-строительного университета; 107031, г. Москва, ул. Большая Дмитровка, д. 24, стр. 1; тел. +7(495) 625-71-63;

факс+7 (495) 650-27-31; e-mail: akimov@raasn.ru, pavel.akimov@gmail.com.

Кайтуков Таймураз Батразович, советник РАACH, доцент, кандидат технических наук, заместитель главного ученого секретаря Российской академии архитектуры и строительных наук; Центральный научно-исследовательский и проектный институт Министерства строительства и жилищно-коммунального хозяйства Российской Федерации; 107031, г. Москва, ул. Большая Дмитровка, д. 24, стр. 1;

тел. +7(495) 625-81-53; факс +7 (495) 650-27-31;

E-mail:kaytukov@raasn.ru, tkaytukov@gmail.com. 